\title{
Organic Fouling Behaviour of Structurally and Chemically Different Forward Osmosis Membranes - A study of Cellulose Triacetate and Thin Film Composite Membranes
}

Nur Muna Mazlan ${ }^{a}$, Patrizia Marchetti $^{a}$, H A Maples ${ }^{b}$, Boram Gu $^{a}$, Santanu Karan ${ }^{a}$, A Bismarck ${ }^{a, b}$, and Andrew G Livingston* ${ }^{a}$

${ }^{\mathrm{a}}$ Department of Chemical Engineering Imperial College London South Kensington Campus

London SW7 2AZ

UK

${ }^{\mathrm{b}}$ Polymer \& Composite Engineering (PaCE) Group Institute for Materials Chemistry \& Research University of Vienna Waehringer Strasse 42

A-1090 Vienna

Austria

*Corresponding author.

Tel: +44 (0)20 75945582

Fax: +44 (0)20 75945639

E-mail address: a.livingston@imperial.ac.uk (A.G. Livingston). 


\section{Abstract}

The HTI cellulose triacetate (CTA) and novel thin film composite (TFC) membranes are used to study the multifaceted interactions involved in the fouling and cleaning of forward osmosis (FO) membranes, using calcium alginate as a model foulant. Results show that fouling on the TFC membrane was more significant compared to CTA, arising from a variety of factors associated with surface chemistry, membrane morphology and structural properties. Interestingly, it was observed that in FO mode, membrane surface properties dominated over fouling layer properties in determining fouling behaviour, with some surface properties (e.g. surface roughness) having a greater effect on fouling than others (e.g. surface hydrophilicity). In pressure retarded osmosis (PRO) mode, structural properties of the support played a more dominant role whereby fouling mechanism was specific to the foulant size and aggregation as well as the support pore size relative to the foulant. Whilst pore clogging was observed in the TFC membrane due to its highly asymmetric and porous support structure, fouling occurred as a surface phenomenon on the CTA membrane support layer. Besides pore clogging, the severe fouling observed on the TFC membrane in PRO mode was due to a high specific mass of foulant adsorbed in its porous support. It was observed that a trade-off between enhanced membrane performance and fouling mitigation is apparent in these membranes, with both membranes providing improvement in one aspect at the expense of the other. Hence, significant developments in their surface and structural properties are needed to achieve high anti-fouling properties without compromising flux performance. Measured fouling densities on the studied surfaces suggest that there is not a strong correlation between foulant-membrane interaction and fouling density. Cleaning results suggest that physical cleaning was more efficient on the CTA membrane compared to the TFC membrane. Further, they implied that despite different mechanisms of fouling and quantities of foulant adsorbed in FO membranes, FO is a resilient process with high cleaning efficiencies and fouling reversibility.

Keywords: Forward osmosis; Organic fouling; Fouling reversibility; Cellulose triacetate; Thin film composite. 


\subsection{Introduction}

After debate on the low energy benefits of FO, recent studies have shown that FO generally does not consume less energy compared to RO, specifically where pressure-driven membrane processes are used for the draw solution recovery stage [1, 2]. In a recent paper [3], we concluded that there was effectively no difference in the energy consumption between FO and RO for seawater desalination when nanofiltration was used for the draw recovery. However FO may offer other advantages over RO; for example a major advantage of FO could derive if it had a lower fouling propensity, and several publications have demonstrated the advantages of FO over pressure-driven membrane processes in mitigating fouling [1, 4-12]. They conclude that the lower fouling propensity and high fouling reversibility in FO are attributed to the less-compact fouling layer formed as a result of the absence of hydraulic pressure. The majority of these studies were conducted with commercial CTA membranes because no high performing TFC-FO membranes were commercially available until recently. In recent years, HTI has commenced commercial production of a TFC membrane with a tailor-made support structure to suit FO applications [13-15]. This HTI-TFC membrane is thought to have superior performance and anti-fouling properties $[16,17]$ in addition to a broad $\mathrm{pH}$ tolerance range compared to the HTI-CTA membrane. As it is relatively new, the HTI-TFC membrane has not been widely studied in detail. Alongside production of the commercial HTI-TFC membrane, there has been a rise in the design and fabrication of TFC membranes with tailor-made properties suited for use in FO applications [14, 18-21].

Utilising the HTI-TFC and HTI-CTA membranes, this study systematically investigates multiple contributing factors affecting FO fouling, using calcium alginate as a model organic foulant. We explore how factors including fouling layer properties, membrane surface properties and membrane structural properties are linked to the fouling and cleaning behaviour of these membranes. The effects of process hydrodynamic conditions on fouling layer properties are also investigated. Quantitative methods are introduced for the measurement of FO fouling layer properties such as the specific mass of foulant adsorbed and fouling layer density. These methods provide an avenue for correlating these 
properties with fouling behaviour and process conditions. Various analytical and membrane characterisation techniques such as Atomic Force Microscopy (AFM) and X-ray Photoelectron Spectroscopy (XPS), were utilised to further the understanding of the relationship between membrane surface properties and FO fouling propensity.

This study addresses the question of whether the superior flux and rejection performance of the HTITFC membrane, which results from its improved surface and structural properties, can be extended to its performance under fouling conditions, or if there is an underlying trade-off between these improved membrane properties and fouling performance in FO, which needs to be addressed when designing high-performance TFC FO membranes.

\subsection{Materials and Methods}

\subsection{FO Membranes}

The forward osmosis membranes used in this study were obtained from Hydration Technologies, Inc. (Albany, OR). The HTI-CTA has an asymmetric structure and is made of cellulose acetate supported by an embedded polyester mesh. The total thickness of the membrane is $\sim 50 \mu \mathrm{m}$. The HTI-TFC membrane resembles a typical TFC membrane with a tailor-made support structure to suit FO applications. A polyester mesh is embedded in the support for added mechanical strength. The total thickness of the membrane is $100 \mu \mathrm{m}[13]$.

\subsection{Organic Foulant}

Sodium alginate (Sigma-Aldrich, Lot number: MKBL9077V) used in this study was extracted from brown algae. The foulant represents polysaccharides that constitute a major fraction of soluble microbial products in secondary wastewater effluents. Its molecular weight is specified by the manufacturers as, between 12 to $80 \mathrm{kDa}$. The foulant was received in powder form. A stock solution of 10 g. $\mathrm{L}^{-1}$ was prepared by dissolving the foulant in DI water. The solution was mixed for 24 hours to 
ensure complete dissolution of the alginate. Once dissolved, the alginate solution was stored in a sterilized glass bottle at $4{ }^{\circ} \mathrm{C}$.

\subsection{Test Solutions}

The composition of the feed and draw solutions used in this study are shown in Table $1 . \mathrm{CaCl}_{2}$ (Sigma-Aldrich, UK), was added to the alginate feed solution to form intermolecular bridges between neighbouring alginate molecules, leading to the formation of a cross-linked gel network following the complexation of alginate with the $\mathrm{Ca}^{2+}$ ions. The ambient $\mathrm{pH}$ of the alginate feed solution was $\mathrm{pH} 6.8$. Different draw solution concentrations were needed for the different membranes and orientations to achieve the same initial flux for the fouling experiments. This is to ensure that the effect of initial flux on membrane fouling was eliminated.

\begin{tabular}{|c|c|c|c|c|c|}
\hline \multicolumn{6}{|c|}{ Baseline Experiment } \\
\hline Test Solutions & Mode & Membrane & Concentration & Units & Notes \\
\hline Feed solution & $\begin{array}{l}\text { FO, } \\
\text { PRO }\end{array}$ & CTA, TFC & 50 & $\mathrm{mM}$ & $\mathrm{NaCl}$ \\
\hline \multirow{4}{*}{ Draw solution } & \multirow{2}{*}{ FO } & CTA & 4.00 & \multirow{4}{*}{ M } & \multirow{4}{*}{$\mathrm{NaCl}$} \\
\hline & & TFC & 2.75 & & \\
\hline & \multirow{2}{*}{ PRO } & CTA & 1.50 & & \\
\hline & & TFC & 1.15 & & \\
\hline \multicolumn{6}{|c|}{ Fouling Experiment } \\
\hline & $\mathrm{E} \Omega$ & & 50 & $\mathrm{mM}$ & $\mathrm{NaCl}$ \\
\hline Feed solution & $\begin{array}{l}\text { PRO } \\
\text { PRO }\end{array}$ & CTA, TFC & 0.5 & $\mathrm{mM}$ & $\mathrm{CaCl}_{2}$ \\
\hline & & & 200 & mg. $L^{-1}$ & Alginate \\
\hline \multirow{4}{*}{ Draw solution } & \multirow{2}{*}{ FO } & CTA & 4.00 & \multirow{4}{*}{ M } & \multirow{4}{*}{$\mathrm{NaCl}$} \\
\hline & & TFC & 2.75 & & \\
\hline & \multirow{2}{*}{ PRO } & CTA & 1.50 & & \\
\hline & & TFC & 1.15 & & \\
\hline
\end{tabular}

Table 1: Feed and draw solution compositions used in this study. 


\subsection{Membrane Pretreatment}

TFC membranes used in the fouling experiments were wetted with a $50 \%$ solution of methanol (VWR, UK) for 60 min to ensure complete wetting of the less hydrophilic TFC support [22]. Following methanol pretreatment, the membrane was thoroughly rinsed and stored in DI water overnight prior to the fouling experiment.

The CTA membrane was not prewetted since it is easily hydrated when exposed to water. However, the membrane was soaked in DI water for 24 hours before use. Both membranes were soaked in water to remove the layer of preserving agent, glycerine (Figure S-1 of the electronic supplementary information (ESI)).

\subsection{Membrane Characterisation}

\subsubsection{Scanning Electron Microscopy (SEM)}

Aerial and cross-sectional images of the pristine, fouled and cleaned membranes were taken with a high resolution, field-emission gun scanning electron microscope (FEGSEM), LEO Gemini 1525 (Carl Zeiss). At least two locations and membrane samples were imaged to ensure reproducibility. For cross-sectional images, membrane samples were prepared by soaking in ethanol and then freezefractured in liquid nitrogen to preserve the pore structure, before drying in air and being carefully cut with a scissors to avoid any damage. Prior to imaging, the samples were coated with a $10 \mathrm{~nm}$ thick layer of chromium sputtered (Q150T turbo-pumped sputter coater, Quorum Technologies Ltd.) under an $\mathrm{Ar}$ atmosphere $\left(2 \times 10^{-2} \mathrm{mbar}\right)$.

\subsubsection{X-ray Photoelectron Spectroscopy (XPS)}

X-ray photoelectron spectroscopy (XPS) was conducted on the TFC and CTA active surfaces by the Oxford Materials Characterisation Service and BegbrokeNano, Department of Materials, Oxford University. The survey spectra and core level XPS spectra were recorded from at least two different spots on the membrane surface of size $400 \mu \mathrm{m}$ to ensure reproducibility. 200 Watt unmonochromated 
$\mathrm{Mg}$ X-ray excitation was used. The analyser was operated at constant pass energy of $200 \mathrm{eV}$ for wide scans and $20 \mathrm{eV}$ for detailed scans. Data processing was performed using CasaXps.

\subsubsection{Contact Angle}

Contact angle measurements on the membrane surface were performed at room temperature with an Easy Drop Instrument (Kruess) using a sessile drop method. All membranes were dried at room temperature prior to measurement. The contact angle values are reported as an average of three measurements, each using a droplet volume of about $5-10 \mu \mathrm{L}$. At least two membrane samples for each surface and three different locations per sample, were measured for reproducibility.

\subsubsection{Atomic Force Microscopy (AFM)}

Atomic Force Microscopy, Dimension 3100 (Veeco Instruments Inc., New York) was used to measure the surface roughness of the membranes' active and support layers. The images were captured using tapping mode with PointProbe ${ }^{\circledR}$ Plus silicon-SPM probes (PPP-NCH, Nanosensors ${ }^{\mathrm{TM}}$, Switzerland) with a typical tip radius of less than $7 \mathrm{~nm}$. A sampling resolution of not more than 512 points per line and a speed of $0.2-1 \mathrm{~Hz}$ were used to capture the images. 'Gwyddion 2.38 SPM data visualisation and analysis software' was used to analyse the AFM images. An average value for rootmean-square roughness $\left(\mathrm{R}_{\mathrm{ms}}\right)$ was taken from four measurements across the membrane surface. At least two membrane samples for each surface were measured for reproducibility.

\subsubsection{Zeta Potential}

The zeta potential of the membrane surface was measured using an Electrokinetic Analyzer (EKA) for Solid Surface Analysis, SurPASS (Anton Paar GmbH, Graz, Austria). $0.5 \mathrm{mM} \mathrm{NaCl}$ was used as the electrolyte, a lower concentration than that used in the fouling solution (i.e. $50 \mathrm{mM} \mathrm{NaCl}$ ) to avoid charge screening effects and enable accurate measurements of the zeta potential. $0.5 \mathrm{mM} \mathrm{CaCl}_{2}$ and sodium alginate were added to the test solution to observe the effects of cation adsorption and reflect the actual electrokinetic property of the membrane during fouling tests, respectively. $0.05 \mathrm{M} \mathrm{HCl}$ and $\mathrm{NaOH}$ were used to adjust the solution $\mathrm{pH}$ via automatic titration. Before the beginning of each 
measurement or after $\mathrm{pH}$ adjustment of the test solution, the cell was thoroughly flushed with the test solution to remove air bubbles, provide accurate measurements and achieve the desired test solution chemistry. All zeta potential measurements were carried out at $25 \pm 2{ }^{\circ} \mathrm{C}$. The membrane surfaces were tested for reproducibility.

\subsubsection{Intrinsic Properties}

The pure water permeance and salt rejection of the membranes studied were measured using an RO cross-flow rig with an applied pressure of 20 bar, temperature of $30{ }^{\circ} \mathrm{C}$ and cross-flow rate of $40 \mathrm{~L} \cdot \mathrm{h}^{-1}$. The permeance was calculated by measuring permeate volume (V) collected per unit area $\left(A_{m}\right)$ per unit time (t) per unit pressure difference $(\Delta P)$ according to the following equation:

$$
J_{P, R O}=\frac{V}{A_{m} \cdot t \cdot \Delta P}\left[\text { unit: } L \cdot m^{-2} \cdot h^{-1} \cdot \text { bar }^{-1}\right]
$$

Equation 1

The salt rejection was calculated as follows:

$$
R_{i}=\left(1-\frac{C_{P, i}}{C_{R, i}}\right) \times 100[\%]
$$

Equation 2

whereby, $C_{P, i}$ and $C_{R, i}$ correspond to the concentration of salt in permeate and retentate, respectively. Three samples of each membrane were tested for reproducibility.

\subsection{Foulant Characterisation}

\subsubsection{Hydrodynamic Diameter and Surface Charge}

The hydrodynamic diameter and surface charge of calcium alginate were measured using a Zetasizer Nano ZS (Malvern Instruments, UK). An average of three measurements was taken at $30{ }^{\circ} \mathrm{C}$, which corresponds to the temperature of the feed solution in fouling tests. The hydrodynamic diameter of calcium alginate in the feed solution was $15 \pm 3 \mathrm{~nm}$. The zeta potential of sodium alginate and calcium alginate were $-56 \pm 5 \mathrm{mV}$ and $-20 \pm 2 \mathrm{mV}$, respectively. 


\subsubsection{Specific Mass of Foulant Adsorbed}

The specific mass of alginate adsorbed per unit volume of permeate produced following the fouling experiment was calculated using the following equation:

$$
\text { Specific mass of alginate, } m_{s, \text { alg }}=\frac{\left(C_{f, t=0} \times V_{f, t=0}\right)-\left(C_{f, t=27} \times V_{f, t=27}\right)}{V_{P}}\left[\text { unit: } m g . L^{-1}\right]
$$

Equation 3

whereby $C_{f, t=0}$ and $C_{f, t=27}$ are the foulant concentrations at the start $(\mathrm{t}=0$ hour) and finish $(\mathrm{t}=27$ hours) of the fouling experiments, $V_{f, t=0}$ and $V_{f, t=27}$ are the feed volumes at the start ( $\mathrm{t}=0$ hour) and finish ( $\mathrm{t}=27$ hours) of the fouling experiments, and $V_{P}$ is the permeate volume.

The initial and final foulant concentrations were measured using a Total Organic Carbon Analyser, TOC- $\mathrm{V}_{\mathrm{CPN}}$ (Shimadzu, UK), using the non-purgeable organic carbon (NPOC) method. At least one repeat experiment was performed for every membrane tested, and a minimum of two measurements per experiment was conducted to ensure reproducibility of results. An inspection of the system performed following the fouling experiment confirmed that all foulant lost from the feed solution was deposited on the membrane surface and none was deposited in the feed solution channel or tank.

\subsubsection{Fouling Layer Density}

The density of the fouling layer adsorbed on the membrane surface was measured using a modified technique for measuring densities of biofilms [23, 24]. Following the fouling experiment, the fouled membrane was left to dry overnight. A known area of the fouled membrane was selected and its dry mass measured using an analytical balance. The selected membrane area was hydrated using DI water and the wet thickness of the alginate gel was measured using an Easy Drop Instrument (Kruess). Following the thickness measurement, the alginate gel was thoroughly rinsed off the membrane surface, and the cleaned membrane was dried in the oven at $80{ }^{\circ} \mathrm{C}$ for at least three hours until there was no further mass change. The mass of the dried, cleaned membrane was measured and subtracted 
from the mass of the fouled membrane to give the foulant mass adsorbed. Fouling density was then calculated using the following equation [23]

$$
\frac{m_{f, d}}{\delta_{f, w} \times A_{m, s}}\left[\text { unit: } \mathrm{mg} \cdot \mathrm{cm}^{-3}\right]
$$

Equation 4

whereby $m_{f, d}$ and $\delta_{f, w}$ are the dry mass and wet thickness of the foulant, and $A_{m, s}$ is the selected area for the density measurement. At least two membrane samples for each surface were measured for reproducibility.

\subsection{FO Cross-flow Setup}

Figure 1 (a) shows a schematic of the experimental setup used for the FO experiments in this study. This setup consists of a circular stainless steel cross-flow cell with an open area of $44 \mathrm{~cm}^{2}$ available for water permeation. The cross-flow cell was custom built with equally structured channels on both sides of the membrane, each $1 \mathrm{~cm}$ deep by $7.5 \mathrm{~cm}$ in diameter (Figure 1 (b)). No spacer was used in the channels, however, the circular geometry of the cell provides a greater degree of mixing to reduce external concentration polarisation. Feed and draw solution flow rates were fixed at $24 \mathrm{~L} \cdot \mathrm{h}^{-1}$ using variable speed gear pumps (Micropump GJ-N23, Vancouver, USA). No hydraulic pressure was applied on either side of the membrane. The external mass transfer coefficient in the cross-flow cell at $24 \mathrm{~L}^{-\mathrm{h}^{-1}}$ is $4.4 \times 10^{-5} \mathrm{~m} \cdot \mathrm{s}^{-1}$. The draw solution tank was placed on a digital weighing scale (Denver S8001) and the weight change was monitored using the Denver Transmit data transfer software. The weight change was used to calculate water flux through the membrane:

$$
J_{P, F O_{t_{i}}}=\frac{M_{t_{i}}-M_{t_{i-1}}}{\left(t_{i}-t_{i-1}\right) \cdot \rho \cdot A_{m}}=\frac{\Delta M_{t_{i}}}{\Delta \mathrm{t}_{i} \cdot \rho \cdot A_{m}}\left[\text { unit: } L . m^{-2} \cdot h^{-1}\right]
$$

\section{Equation 5}

whereby, $J_{P, F O_{t_{i}}}$ is the FO permeate flux, $\Delta M_{t_{i}}$ is the weight change of the solution over a time interval, $\rho$ is the solution density, $A_{m}$ is the membrane area and $\Delta t_{i}$ is the discrete time interval.

Feed and draw solution temperatures were held constant at $30 \pm 1^{\circ} \mathrm{C}$ using a water bath. 


\subsection{Fouling and Cleaning Procedure}

A new membrane coupon was loaded into the FO cell before each experiment. $2 \mathrm{~L}$ of feed solution (without foulant) and draw solution were added to the feed and draw solution tanks. The feed and draw solutions were circulated for an hour at a fixed flowrate of $24 \mathrm{~L} \cdot \mathrm{h}^{-1}$ until the initial flux of the membrane was stabilised. Next, $200 \mathrm{mg} \cdot \mathrm{L}^{-1}$ of foulant was added to the feed solution. The fouling experiment was run for 27 hours and a data transfer software (Denver Transmit, Germany) was used to monitor weight change of the DS throughout the experiment, which was converted to water flux according to Equation 5. Baseline experiments were conducted to quantify the effect of dilution of the draw solution and corresponding decrease in driving force on flux decline. The baseline experiments followed the same procedure as the fouling experiments, only without any foulant present in the feed solution. The feed and draw solution compositions used in the baseline and fouling experiments are presented in Table 1 of Section 2.3.

Cleaning experiments were conducted immediately after the fouling experiments. The method and conditions used for cleaning are presented in Table 2. Unless otherwise specified, the cleaning experiments were run at $60 \mathrm{~L} \cdot \mathrm{h}^{-1}$ for 15 minutes with DI water as the cleaning solution. During cleaning experiments, both the feed and draw solutions were replaced with DI water to ensure there was no permeate flux through the membrane. After cleaning, flux recovery of the membrane was determined by repeating the initial flux experiment on the cleaned membrane under the same test conditions. In some cases, backwashing was performed as a cleaning mechanism for improved flux recoveries. Unless otherwise stated, backwashing was performed by replacing the draw solution with DI water and feed solution with $1 \mathrm{M} \mathrm{NaCl}$ to achieve sufficiently high back fluxes for foulant removal. The cleaning experiments were repeated using at least two different membrane samples to ensure good reproducibility of results.

\begin{tabular}{|l|c|c|c|c|c|c|c|}
\hline \multicolumn{7}{|c|}{ Cleaning Experiment } \\
\hline Method & Mode & Membrane & Flowrate & Time & $\begin{array}{c}\text { Feed } \\
\text { solution }\end{array}$ & $\begin{array}{c}\text { Draw } \\
\text { solution }\end{array}$ & $\begin{array}{c}\text { No. of } \\
\text { runs }\end{array}$ \\
\hline
\end{tabular}




\begin{tabular}{|c|c|c|c|c|c|c|c|}
\hline $\begin{array}{c}\text { Increased } \\
\text { recirculation } \\
\text { flowrate }\end{array}$ & FO, PRO & CTA, TFC & $60\left({\left.\mathrm{~L} \cdot \mathrm{h}^{-1}\right)}^{-15}\right.$ & $15 \mathrm{~min})$ & DIW & DIW & 2 \\
\hline Backwash & PRO & TFC & $24,60\left({\left.\mathrm{~L} \cdot \mathrm{h}^{-1}\right)}^{-1}\right.$ & $15(\mathrm{~min})$ & $1 \mathrm{M} \mathrm{NaCl}$ & DIW & 2 \\
\hline
\end{tabular}

Table 2: Cleaning method and conditions used in this study.

(a)

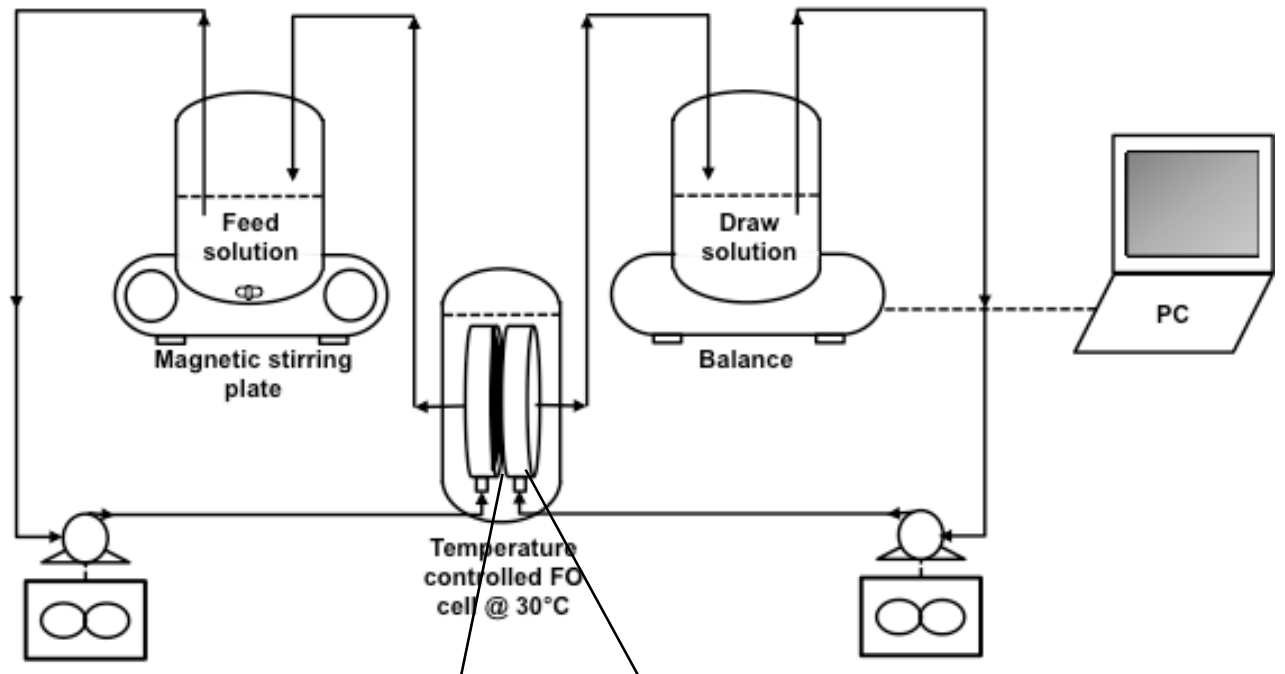

Flow control

(b)

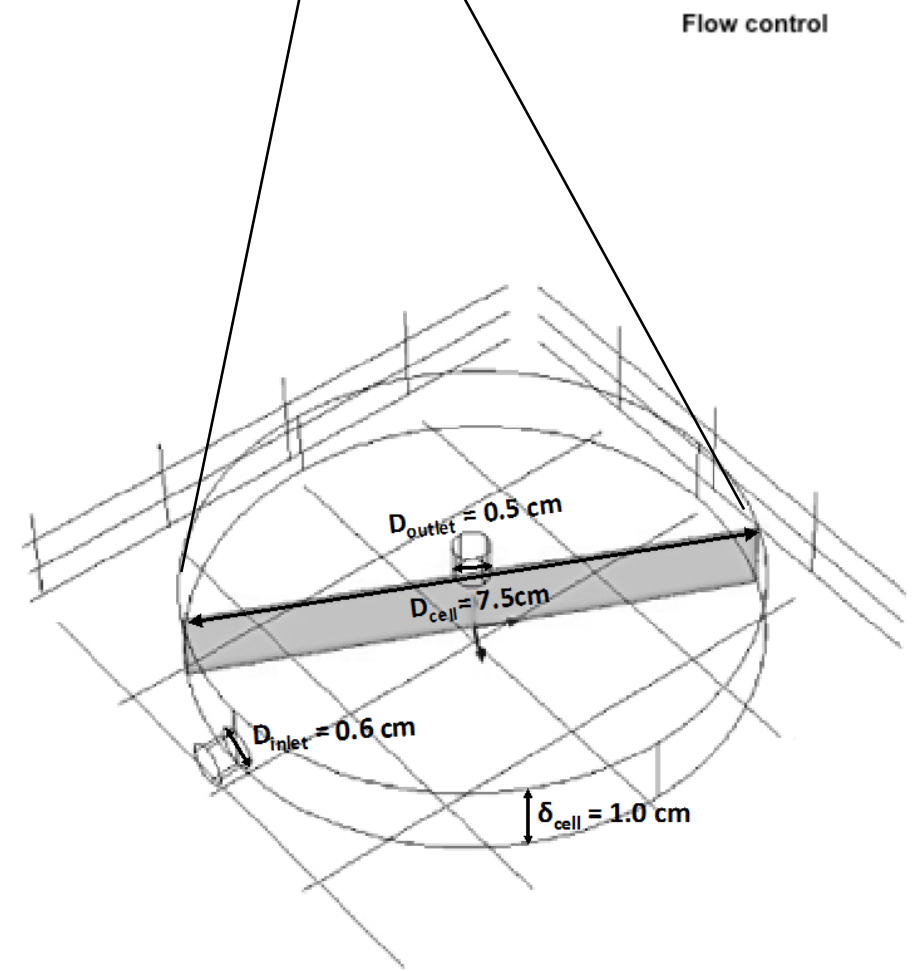

Figure 1: (a) Schematic of the lab scale forward osmosis experimental setup, and (b) schematic of the FO cross-flow cell with cell dimensions 


\subsection{Data Analysis}

The experimental permeate flux data were analysed in terms of specific effects of fouling on the intrinsic membrane permeance, $\mathrm{L}_{\mathrm{p}}$, and solute resistivity to diffusion within the porous support, $\mathrm{K}$. The effects of continuous dilution and concentration of the draw and feed solutions, respectively, as well as the change in concentration at the membrane surface resulting from the closed-loop batch system used, were taken into account.

The permeate flux as a function of membrane permeance and solute resistivity to diffusion is described by Equation 6 and Equation 7 for FO and PRO modes, respectively [25, 26]:

$$
J_{P}=L_{P}\left[\pi_{D, b} \exp \left(-J_{P} K\right)-\pi_{F, b} \exp \left(\frac{J_{P}}{k}\right)\right]\left[\text { unit: } L \cdot m^{-2} \cdot h^{-1}\right]
$$

Equation 6

$$
J_{P}=L_{P}\left[\pi_{D, b} \exp \left(-\frac{J_{P}}{k}\right)-\pi_{F, b} \exp \left(J_{P} K\right)\right]\left[\text { unit: } L \cdot m^{-2} \cdot h^{-1}\right]
$$

Equation 7

whereby, $k$ is the external mass transfer coefficient on the active side [25]:

$$
k=\frac{S h \cdot D}{D_{h}}=a R e^{b} S c^{c}\left(\frac{D_{h}}{L}\right)^{d}\left(\frac{D}{D_{h}}\right)\left[\text { unit: } m \cdot s^{-1}\right]
$$

Equation 8

And $K$ is the solute resistivity to diffusion within the porous support layer, which provides a measure of the extent of internal concentration polarisation (ICP) [25]:

$$
K=\frac{t \tau}{D \varepsilon}=\frac{S}{D}\left[\text { unit: } s . m^{-1}\right]
$$

Equation 9 
The external mass transfer coefficient of the FO cross-flow cell, $k$, was obtained experimentally using a method reported by Peeva et al. [27]. Note that external concentration polarisation (ECP) is not considered on the outer support layer side of the membrane since the thickness of the external boundary layer under the present experimental conditions is much lower (i.e. $<5 \%$ ) than the structural parameter of the membranes studied. Hence, it can be assumed negligible. Moreover, water permeating the backing layer of the membrane already contains some concentration of the draw solute, which mitigates the polarisation effects on the support side since pure water is not entering the bulk solution at the support surface [28, 29].

For Equation 6 to Equation 9, $J_{P}$ represents the permeate flux $\left(L . m^{-2} \cdot h^{-1}\right), L_{p}$ the membrane permeance $\left(L \cdot m^{-2} \cdot h^{-1} \cdot b_{a r}-1\right), K$ is the solute resistivity to diffusion within the support layer $\left(s . m^{-1}\right), k$ is the external mass transfer coefficient $\left(m \cdot s^{-1}\right), \pi_{F, b}$ and $\pi_{D, b}$ are the bulk feed and draw solution osmotic pressures (bar), respectively; $S h, R e$ and $S c$ are the dimensionless Sherwood, Reynolds and Schmidt numbers, respectively; $a, b, c$ and $d$ are constants whose values depend on the system geometry, type of fluid (Newtonian or non-Newtonian) and flow regime; $D$ is the solute diffusion coefficient $\left(m^{2} \cdot s^{-1}\right), D_{h}$ is the hydraulic diameter $(m), L$ is the channel length $(m), t, \tau$ and $\varepsilon$ are the thickness $(m)$, tortuosity and porosity of the support layer, respectively.

\subsubsection{Baseline Data}

The baseline permeance values $\left(L_{P}\right)$ and the structural parameter $(S)$ for the membranes studied in this work were obtained by regressing the experimental flux data for both FO and PRO modes using Equation 6 and Equation 7 for the two orientations, respectively, together with Equation 9. The solute diffusion coefficients, $D$, necessary to obtain the solute resistivity to diffusion within the support layer, $K$, was given as a function of solute concentration (Robinson and Stokes, 1959) [30]. The Isqcurvefit function was used, which solves nonlinear curve-fitting (or data-fitting) problems using a least-square approach in the Matlab environment. The external mass transfer coefficient, $k$, the bulk feed, $\pi_{F, b}$, and the draw solution osmotic pressures, $\pi_{D, b}$, were given as experimental input values. 
The osmotic pressures were calculated over the range of concentrations employed using a corrected van't Hoff equation, which accounts for electrolyte dissociation and ion paring. The quality of the fitting was calculated as the norm of residuals (see Equation 10):

$$
N_{r}=\sqrt{\Sigma_{i}\left(\frac{J_{i}^{\text {exp }}-J_{i}^{\text {calc }}}{J_{i}^{\text {exp }}}\right)^{2}}
$$

\section{Equation 10}

Whereby, $N_{r}$ is the norm of residuals, $J_{i}^{\text {exp }}$ is the experimental flux and $J_{i}^{\text {calc }}$ is the calculated flux.

\subsubsection{Fouling Data}

Differently from the case for the baseline, the analysis of membrane permeance and solute resistivity to diffusion in the presence of fouling is more complicated due to the unknown effect of fouling on both descriptors. Hence, in order to correlate permeance decline with the occurrence of fouling, some assumptions were made for both membranes and orientations. For the CTA membrane in FO and PRO modes and the TFC membrane in FO mode, it was assumed that fouling occurs as a surface phenomenon; whereas for the TFC membrane in PRO mode, it was assumed that the foulant is deposited within the porous support of the membrane. These assumptions were made based on physical cleaning and flux recovery results obtained for both membranes, discussed in further detail in Section 3.3.

When fouling was considered as a surface phenomenon, the effective permeance was obtained by solving Equation 6 and Equation 7 for FO and PRO modes, respectively, together with Equation 9, with supplied values for experimental flux, $J_{P}$, external mass transfer coefficient, $k$, bulk feed, $\pi_{F, b}$, and draw solution osmotic pressures, $\pi_{D, b}$, and diffusion coefficients corresponding to the changing concentrations with time, $D$ (Robinson and Stokes, 1959) [30]. The solute diffusion coefficients were used to calculate $K$ using Equation 9. The structural parameter, $S$, also required for the calculation of 
$K$, was determined by solving Equation 6 and Equation 7, with supplied values for $L_{P}, J_{P}, D, \pi_{D, b}$ and $\pi_{F, b}$ at time 0.

When fouling was assumed to deposit within the porous support, the $S$ parameter could no longer be considered constant due to a reduction in membrane porosity and an increase in membrane tortuosity upon foulant deposition. Hence, the approximation of constant membrane permeance and solute resistivity to diffusion within the support for two consecutive time points, $t_{i}$ and $t_{i+1}$, was made, since one equation was not sufficient. To improve the calculation, above all, in the initial time range where the permeate flux is decreasing rapidly, the permeate flux profile was interpolated by a polynomial, and very small time intervals $\left[\mathrm{t}_{\mathrm{i}}-\mathrm{t}_{\mathrm{i}+1}\right]$, typically $180 \mathrm{~s}$, were used.

\subsection{Results and Discussion}

\subsection{Membrane Characterisation}

\subsubsection{Physical Structure}

Figure 2 shows high resolution SEM images and schematic representations of the two membranes used in this study. Both forward osmosis membranes were obtained from Hydration Technologies, Inc. (Albany, USA). The HTI-CTA membrane (Figure 2 (a) and (c)) has a top rejecting layer followed by a relatively thin and less dense support layer made of cellulose triacetate embedded with a polyester mesh for added mechanical strength. CTA is prevalent throughout the membrane as a denser layer on the rejecting side and a looser layer on the support side. The total thickness of the membrane is approximately $50 \mu \mathrm{m}$. The HTI-TFC membrane (Figure 2 (b) and (d)) is an asymmetric membrane with finger-like morphology, reinforced with a polyester mesh similar to the mesh-embedded CTA membrane. However, the polyester mesh is oriented towards the bottom of the support layer, creating additional macroscopic pores around the mesh lines on the bottom surface [20] as shown in Figure S-2 (c) of the ESI. The total thickness of the membrane is $\sim 100 \mu \mathrm{m}$. 

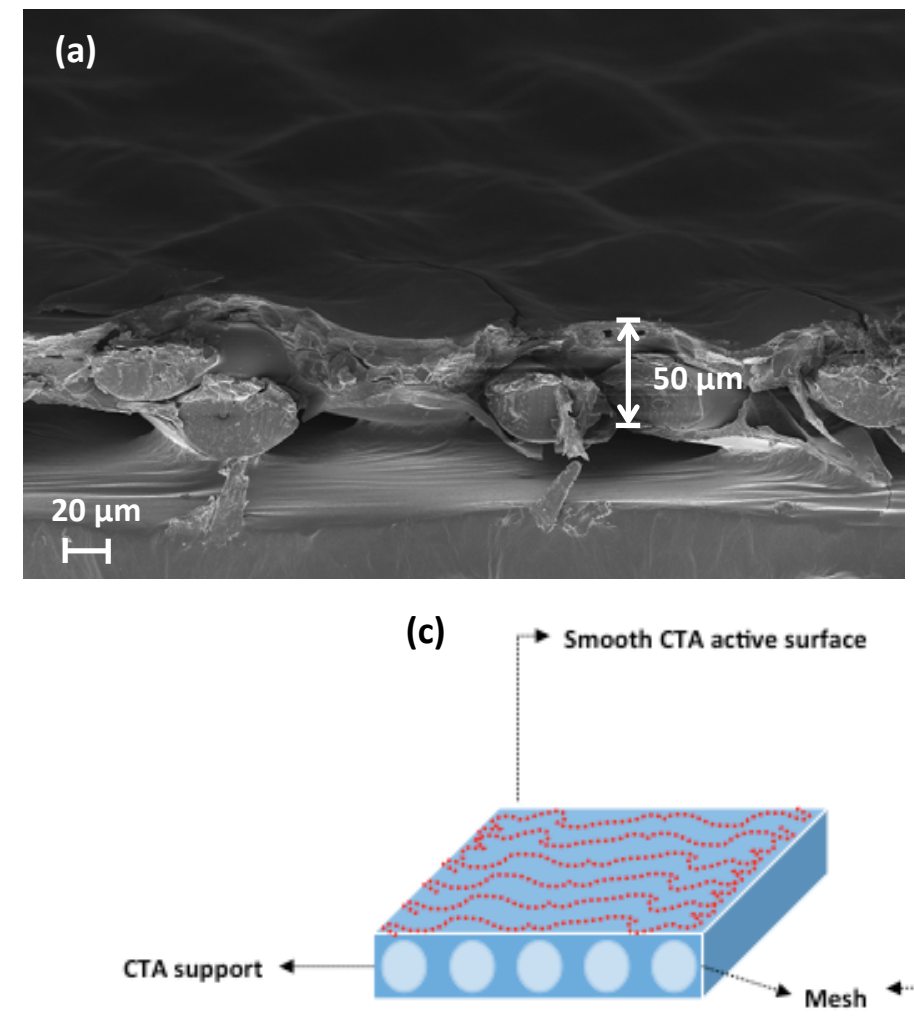

HTI CTA
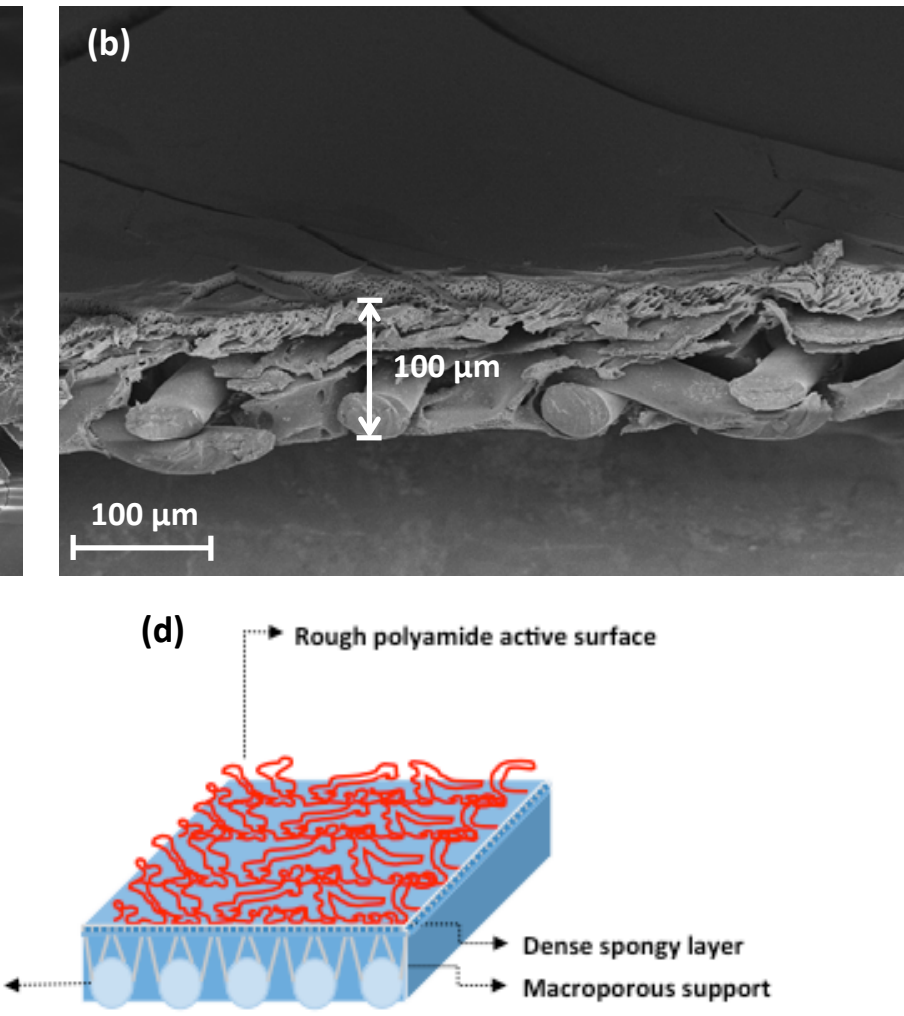

HTI TFC

Figure 2: SEM image and schematic representation of (a,c) HTI-CTA membrane and (b,d) HTI-TFC membrane used in this study. Schematic not drawn to scale.

\subsubsection{Chemical Composition}

An XPS study was conducted on the TFC and CTA active surfaces to determine the differences in chemical composition of these membranes (Figure S-3 and Figure S-4 of the ESI). The survey spectra and narrow scan spectra were analysed to understand the elemental composition and probable chemical functionalities present in the membrane top layers. As presented in our earlier publication [31], the C1s narrow scan spectrum of the TFC membrane was analysed using CasaXPS version 2.3.17. Such analysis revealed the signature amide and carboxyl groups on the TFC active surface (Table 3) similar to the structure of a polyamide. However, there was no nitrogen species or amide bond present on the CTA active surface (Table 3) suggesting that the CTA active layer was not formed from a typical interfacial polymerisation reaction of an acid chloride and amine derivative. In fact, the active and support layers of the CTA membrane were made from the same polymeric 
material by phase inversion of a precursor dope solution [32-34]. Hence, both surfaces are postulated to have a similar chemical composition, unlike the TFC membrane. The XPS study also provides statistical information on the functional groups available for interaction with foulant in solution.

\begin{tabular}{|c|c|c|c|c|c|c|c|c|c|}
\hline \multirow[b]{2}{*}{ Membranes } & \multicolumn{3}{|c|}{ C1s } & \multicolumn{3}{|c|}{ O1s } & \multicolumn{3}{|c|}{ N1s } \\
\hline & $\begin{array}{c}\text { Energy } \\
(\mathrm{eV})\end{array}$ & Species & (\%) & $\begin{array}{c}\text { Energy } \\
(\mathrm{eV})\end{array}$ & Species & (\%) & $\begin{array}{c}\text { Energy } \\
(\mathrm{eV})\end{array}$ & Species & (\%) \\
\hline Cellulose triacetate & 284.8 & $\mathrm{C}-\mathrm{H}, \mathrm{C}-\mathrm{C}$ & 35.7 & \multirow{3}{*}{$\begin{array}{l}532.3 \\
533.4\end{array}$} & \multirow{3}{*}{$\begin{array}{c}\mathrm{C}-\mathrm{O} \\
\mathrm{O}-\mathrm{C}=\mathrm{O}\end{array}$} & \multirow{3}{*}{$\begin{array}{l}42.1 \\
57.9\end{array}$} & & \multirow{3}{*}{ NA } & \multirow{3}{*}{ NA } \\
\hline C: $63.8 \%$ & 286.6 & C-O & 39.4 & & & & NA & & \\
\hline O: $36.2 \%$ & 288.8 & $\mathrm{O}-\mathrm{C}=\mathrm{O}$ & 24.9 & & & & & & \\
\hline \multirow{4}{*}{$\begin{array}{l}\text { Polyamide TFC } \\
\text { C: } 68.7 \% \\
\text { O: } 23.0 \% \\
\text { N: } 8.3 \%\end{array}$} & 285.4 & $\mathrm{C}-\mathrm{CONH}, \mathrm{C}-\mathrm{COO}$ & 17.4 & \multirow{4}{*}{$\begin{array}{l}531.8 \\
533.4\end{array}$} & \multirow{4}{*}{$\begin{array}{l}\mathrm{N}-\mathrm{C}=\mathrm{O} \\
\mathrm{O}-\mathrm{C}=\mathrm{O}\end{array}$} & \multirow{4}{*}{$\begin{array}{c}98.0 \\
2.0\end{array}$} & \multirow{4}{*}{$\begin{array}{l}398.5 \\
400.0\end{array}$} & \multirow{4}{*}{$\begin{array}{l}\mathrm{R}-\mathrm{NH}_{2} \\
\mathrm{~N}-\mathrm{C}=\mathrm{O}\end{array}$} & \multirow{4}{*}{$\begin{array}{c}5.0 \\
95.0\end{array}$} \\
\hline & 286.0 & $\mathrm{C}-\mathrm{N}$ & 11.9 & & & & & & \\
\hline & 287.7 & $\mathrm{~N}-\mathrm{C}=\mathrm{O}$ & 11.9 & & & & & & \\
\hline & 288.8 & $\mathrm{O}-\mathrm{C}=\mathrm{O}$ & 5.5 & & & & & & \\
\hline
\end{tabular}

Table 3: XPS results of the CTA and TFC active surfaces. Binding energies and plausible species were determined from the deconvolution of C1s, O1s and N1s core level XPS spectra.

\subsubsection{Intrinsic Properties}

The intrinsic pure water permeance $\left(\mathrm{L}_{\mathrm{p}}\right)$ and salt rejection of the CTA and TFC membranes are illustrated in Figure 3. The specific values are reported in Table S-1 of the ESI. The CTA membrane has a lower salt rejection (97.7 \%) compared to the TFC membrane (99.0\%), with a corresponding solute permeability coefficient of $0.34 \mathrm{~L} \cdot \mathrm{m}^{-2} \cdot \mathrm{h}^{-1}$ and $0.20 \mathrm{~L} \cdot \mathrm{m}^{-2} \cdot \mathrm{h}^{-1}$, respectively. This indicates that the PA rejecting layer of the TFC membrane exhibits greater selectivity over the CTA membrane.

From Figure 3 (b), it can be seen that the pure water permeance of the pristine TFC membrane is approximately double that of the CTA membrane. After pre-wetting with methanol, the permeance increases to almost three times, suggesting swelling of the polyamide network [35, 36]. Prewetting ensures the membrane porous support is fully water saturated, especially when using TFC membranes with less hydrophilic supports. It also swells the polyamide (PA) layer, thus increasing its permeance. An explanation of the mechanism involved in the swelling of the PA layer is provided in Section 1.0 of the ESI. 
An analysis of variance (ANOVA) was performed to analyse the statistical significance of two variables i.e. membrane type and membrane pretreatment, on the intrinsic separation properties of the membranes studied (Table S-2 of the ESI). Clearly, the type of membrane studied had a significant effect on permeance and rejection due to differences in morphology and structure of the separating and support layers, respectively. It was also statistically revealed that pretreatment with methanol had a significant effect on permeance of the membranes but an insignificant effect on rejection, which is attributed to reasons explained in Section 1.0 of the ESI.

(a)

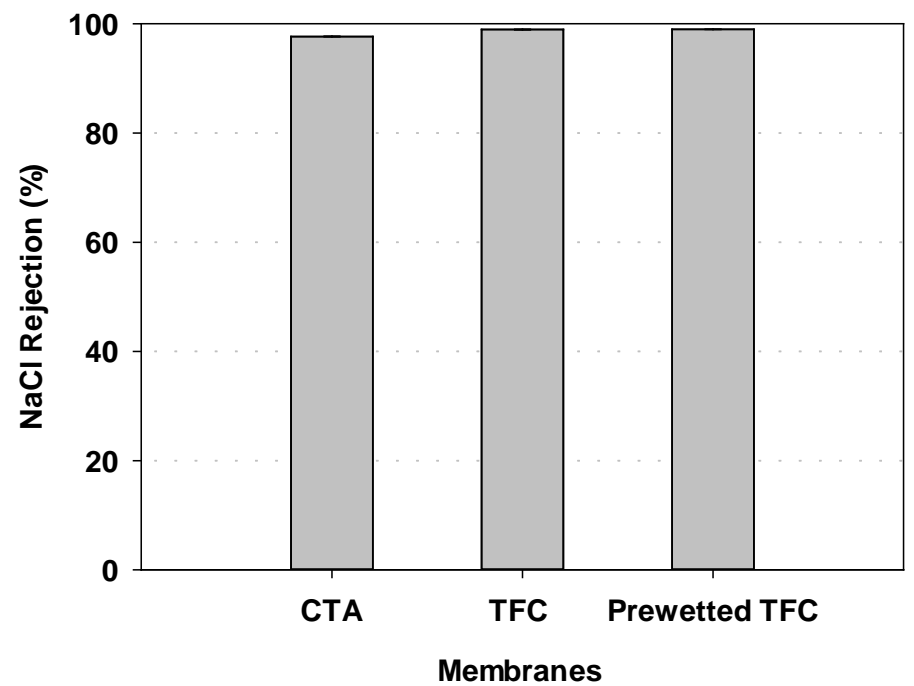

(b)

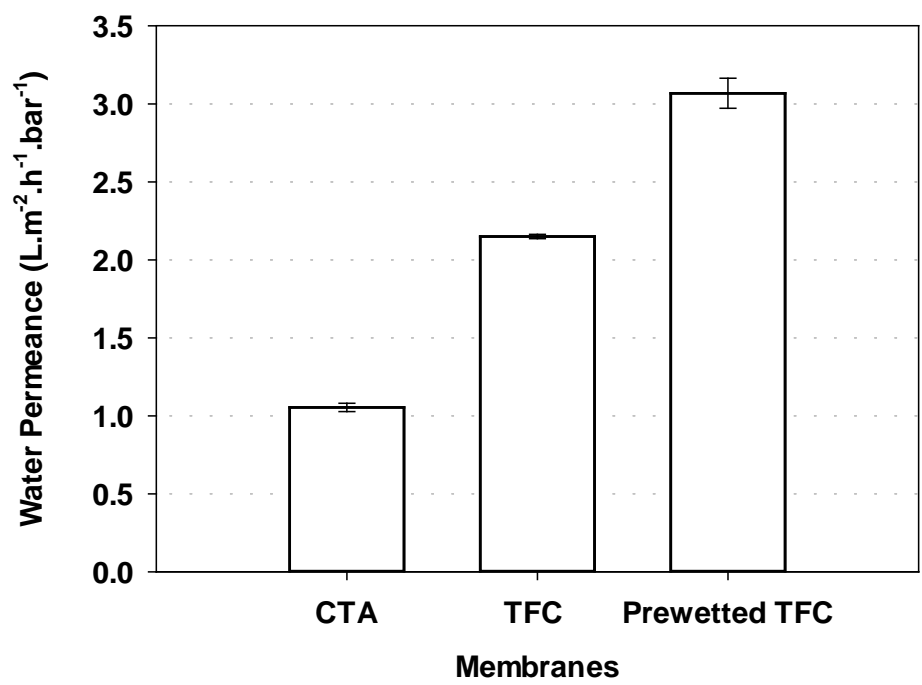

Figure 3: (a) NaCl rejection and (b) pure water permeance of HTI-CTA and TFC membranes measured under RO experimental conditions with an applied pressure of 20 bar, temperature of $30{ }^{\circ} \mathrm{C}$ and cross-flow rate of $40 \mathrm{~L} \cdot \mathrm{h}^{-1}$.

\subsection{Factors Affecting Fouling Behaviour}

Factors affecting the fouling behaviour of the membranes investigated in this study are summarised in Figure 4 and discussed in the following sections. 


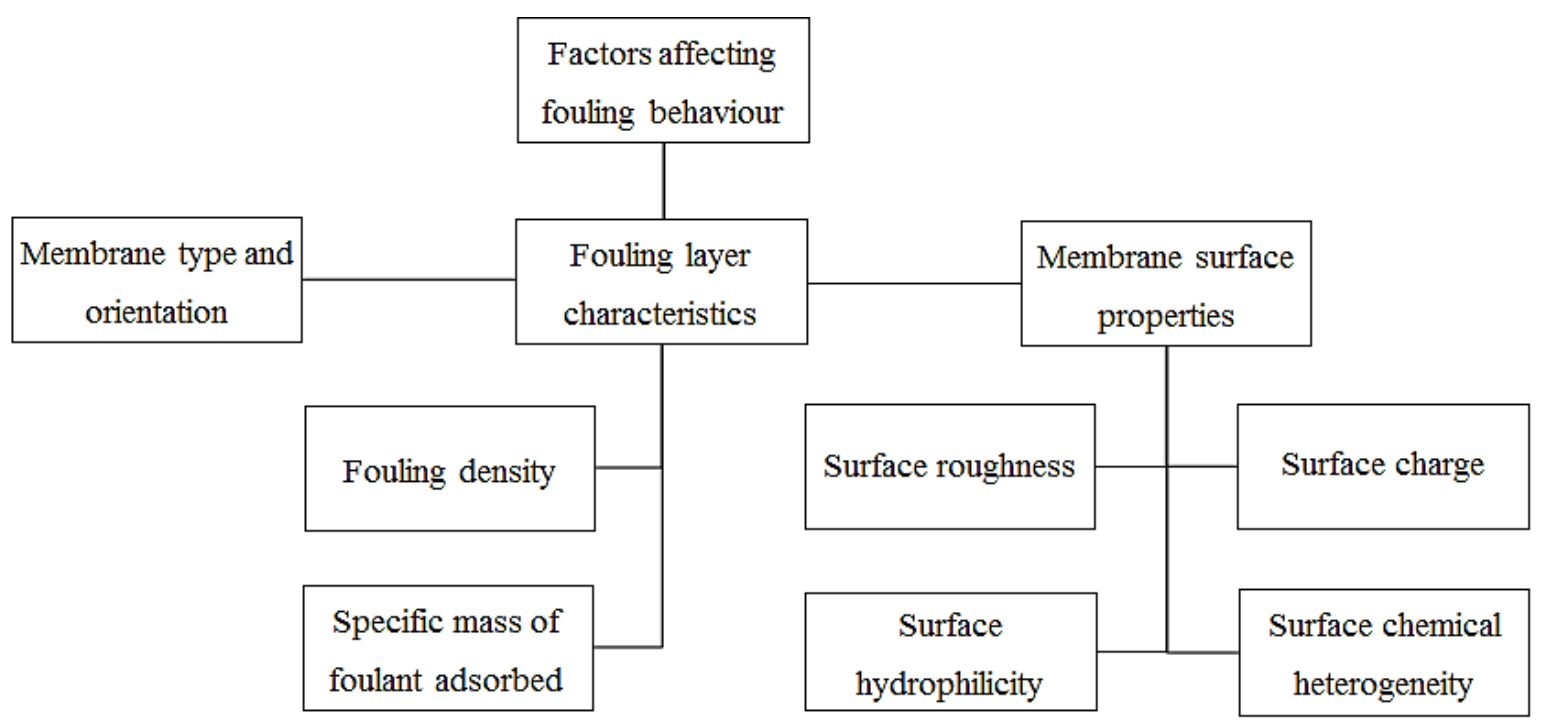

Figure 4: Schematic summarising the factors affecting fouling behaviour of the membranes investigated in this study.

\subsubsection{Membrane Type and Orientation}

Membrane type and orientation have a significant effect on FO fouling. As both the active and support layers can be oriented towards the feed solution, fouling behaviour and the mechanism for foulant deposition can vary significantly if the membrane is asymmetric, i.e. the active and support layers have differing i) structures and ii) chemical composition.

Figure 5 illustrates the baseline permeance and permeance decline due to fouling of the structurally and chemically different HTI membranes in both orientations i.e. active layer facing feed solution (FO mode) and active layer facing draw solution (PRO mode). The effective permeance is plotted as a function of time for baseline and fouling experiments conducted over 27 hours, using data analysis methods explained in Section 2.9. Further details on the baseline analysis results are presented in Section 2.0 of the ESI. 
(a)

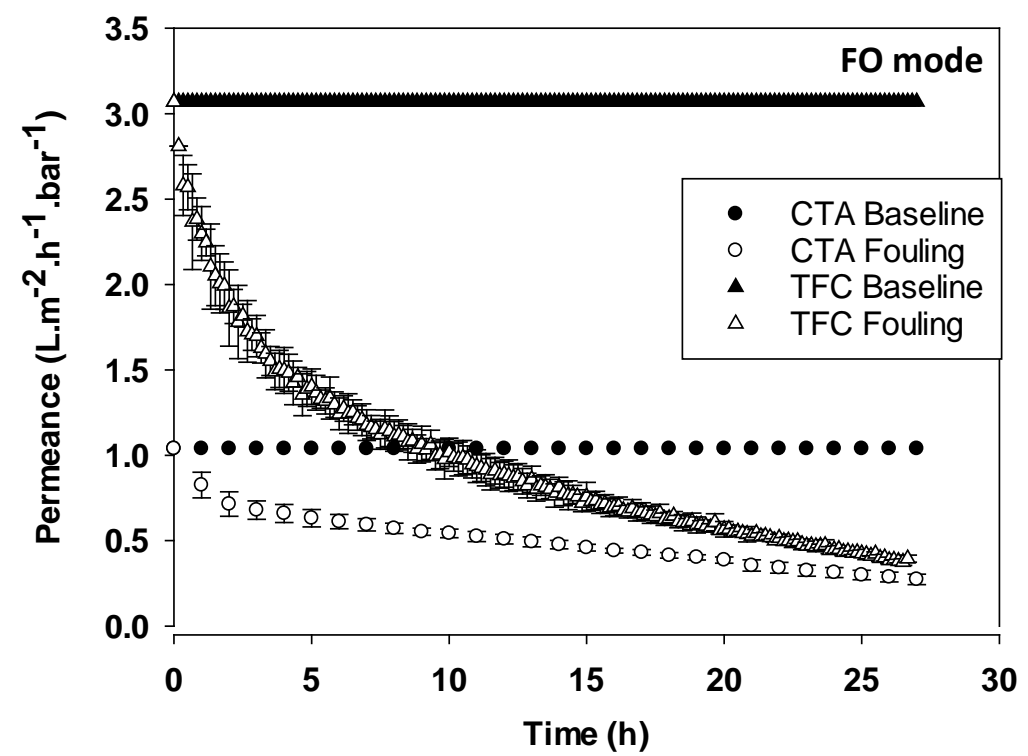

(b)

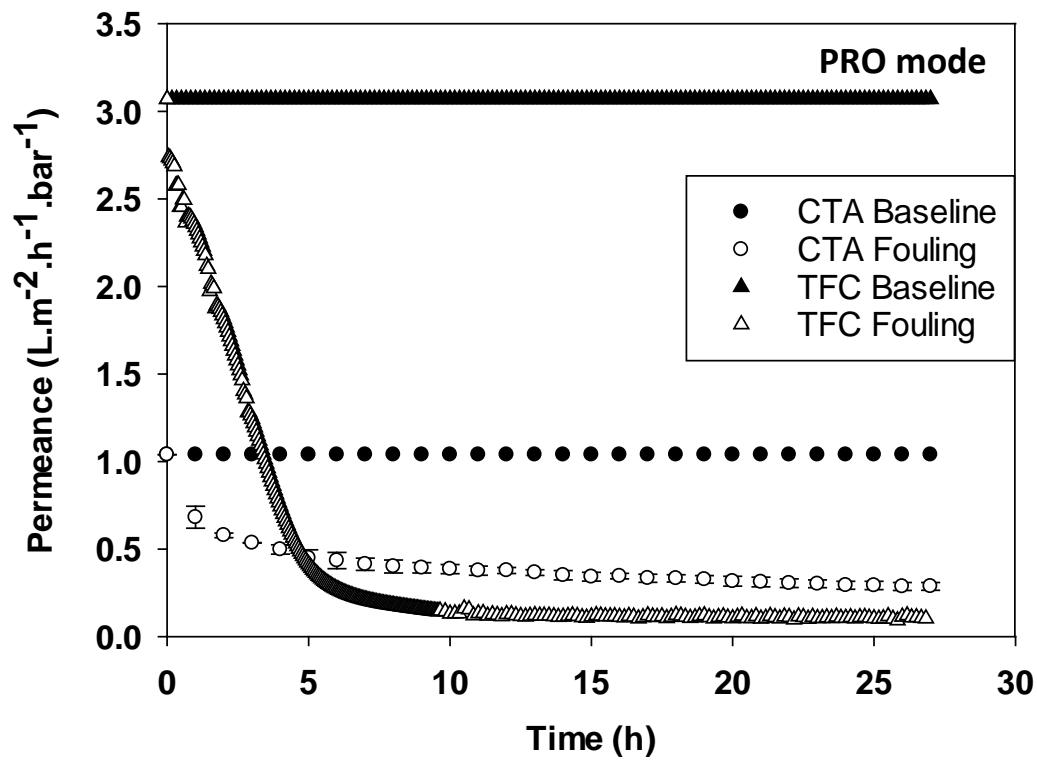

Figure 5: Comparison of fouling behaviour on HTI-TFC and CTA membranes in (a) FO mode and (b) PRO mode. $50 \mathrm{mM}$ NaCl was used as the feed solution in the baseline experiments along with $200 \mathrm{mg} . \mathrm{L}^{-1}$ alginate and $0.5 \mathrm{mM} \mathrm{CaCl}_{2}$ in the fouling experiments. The following concentrations were used for the draw solution to achieve the same initial flux, i) $4 \mathrm{M}$ NaCl for CTA in FO mode, ii) $2.75 \mathrm{M}$ NaCl for TFC in FO mode, iii) $1.5 \mathrm{M}$ NaCl for CTA in PRO mode, and iv) 1.15 M NaCl for TFC in PRO mode. 
Once the foulant is deposited on the membrane surface or in the porous support of the membranes studied, membrane permeance decreases over time due to the hydraulic resistances presented by the adsorbed foulant layer. SEM images of the membranes before and after fouling and cleaning are shown in Figure 6 (a-h) and Figure 7 (a-j).

The extent of membrane fouling is indicated by the magnitude of deviation of the fouling curve from the baseline curve in Figure 5. A greater extent of fouling is observed on the TFC membrane compared to the CTA membrane in FO mode (Figure 5 (a)). SEM images show a visible fouling layer on the surfaces of both membranes (Figure 6 (b) and Figure 7 (b)) following the 27 hour fouling experiment. It can be observed from the fouling curve in Figure 5 (a) that there is a greater decline in membrane permeance initially as the foulant is deposited on the membrane surface. This decline decreases with time, as a more stable, uniform fouling layer is formed across the membrane.

Fouling on the CTA membrane was comparable in both orientations (Figure 5 (a) and (b)). Since the active and support layers of the CTA membrane were fabricated from the same polymeric material [32-34] and are similar in chemical composition, it is proposed that foulant-membrane interactions were similar in both orientations and fouling occurred as a surface phenomenon on the CTA membrane (Figure S-6 (a) and (b) of the ESI). Surface fouling was observed on the CTA support layer due to the relatively smooth (Figure S-7 (b) of the ESI) and dense morphology of the support which is unlike the porous structure of the TFC support layer. It is also attributed to calcium alginate forming a highly structured gel upon aggregation. This is shown in Figure 6 (e) and (h), whereby a visible fouling layer was observed on the membrane surface, which was easily removed by cleaning with DI water at increased cross-flow velocity as illustrated in Section 3.3. However, it is postulated that for foulants with less significant calcium binding effects and smaller particle sizes relative to the pore size of the CTA support layer such as bovine serum albumin (BSA) and Aldrich humic acid (AHA), fouling on the CTA membrane would be more severe in PRO mode [5]. 
A visible fouling layer was not observed on the TFC support surface other than a small amount covering $\sim 2-5 \%$ of the membrane surface shown in Figure 7 (e). Additionally, cleaning conditions had to be modified to include backwashing, as increasing cross-flow velocity alone was insufficient to achieve a comparable flux recovery with the CTA membrane (Section 3.3 and 3.3.1). This indicates that fouling occurred by severe internal clogging of the porous support due to the presence of macropores around the mesh lines of the TFC membrane (Figure S-2 (c) of the ESI), which is reflected in the significant permeance decline compared to the CTA membrane (Figure 5 (b)). Internal clogging reduces the porosity of the support layer resulting in a consequent increase in structural parameter and ICP. This results in severe flux reduction as it is exponentially dependent on the degree of ICP [37]. Following the steep decline in membrane permeance, a steady, almost constant permeance was observed after 10 hours, indicating that fluxes through the membrane were too low to effect a sufficient permeation drag, thus preventing further foulant deposition within the support.

Fouling was less severe on the TFC membrane in FO mode compared to PRO mode as it occurred as a surface phenomenon in FO mode. Besides pore clogging and the increased effect of the S parameter in PRO mode, the enhanced effects of cake-enhanced osmotic pressure [7] due to lack of shear and poor salt diffusion in the porous support also contributed to the greater flux decline in PRO mode. 
Before fouling

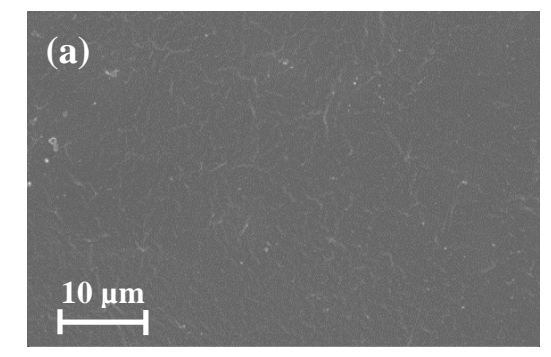

\section{(d)}

Bottom surface

$10 \mathrm{mim}$

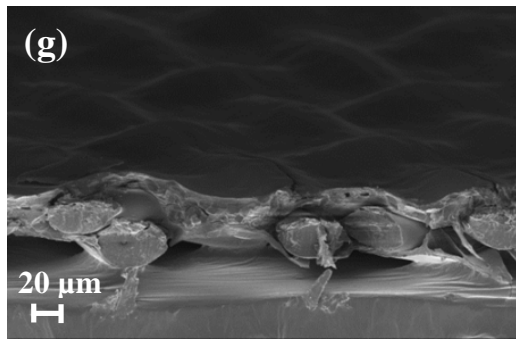

After fouling
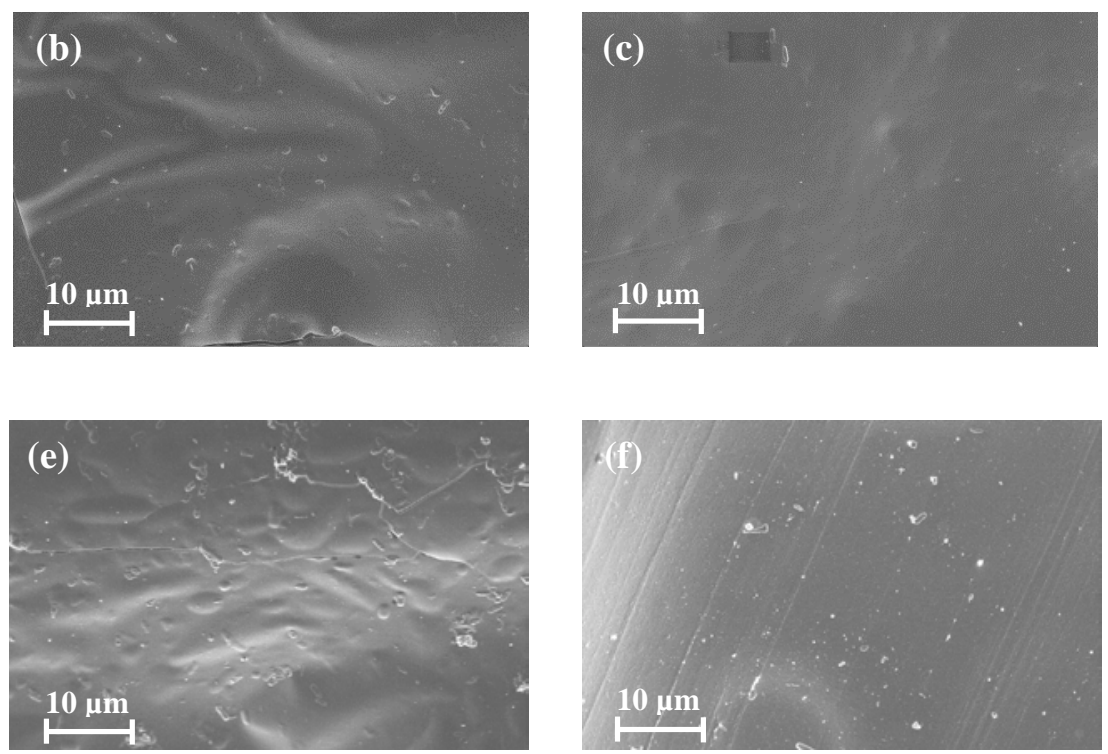

After cleaning

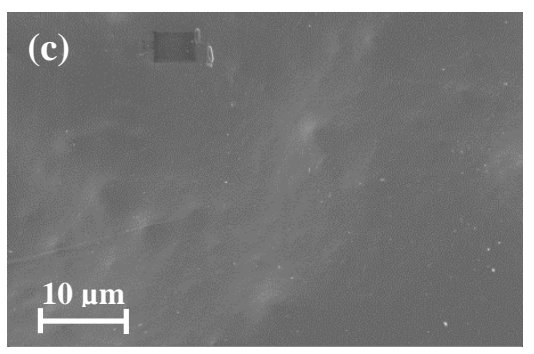

(h)

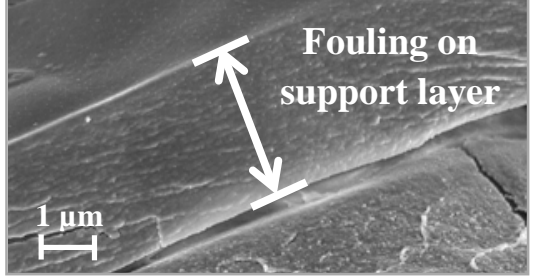

Figure 6: SEM micrographs of pristine, fouled and cleaned CTA membranes; (a-c) top surface, (d-f) bottom surface, and (g-h) cross-sectional micrographs. 
Before fouling
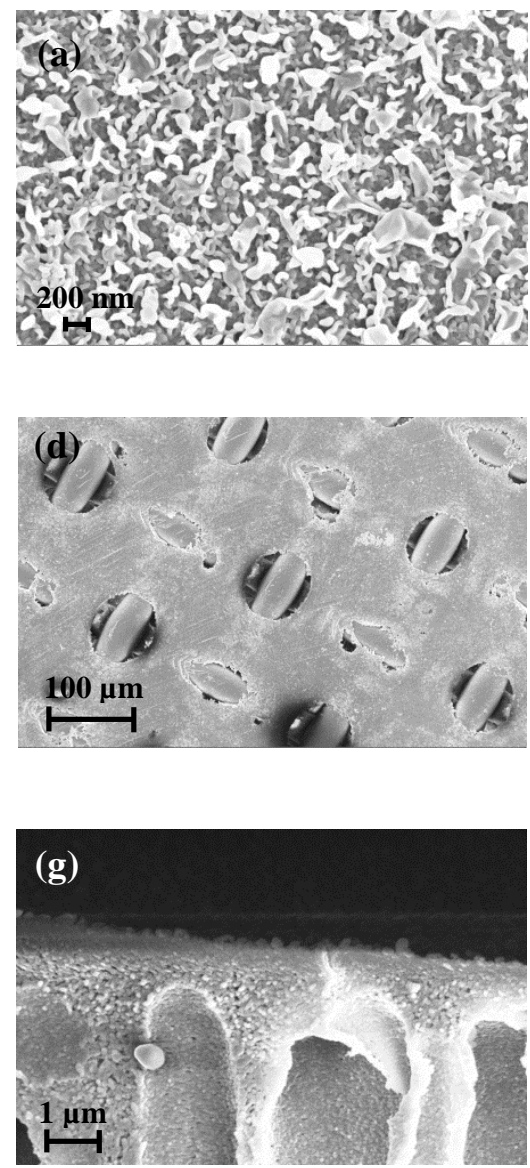

Cross-section: Active layer

Cross-section: Support layer

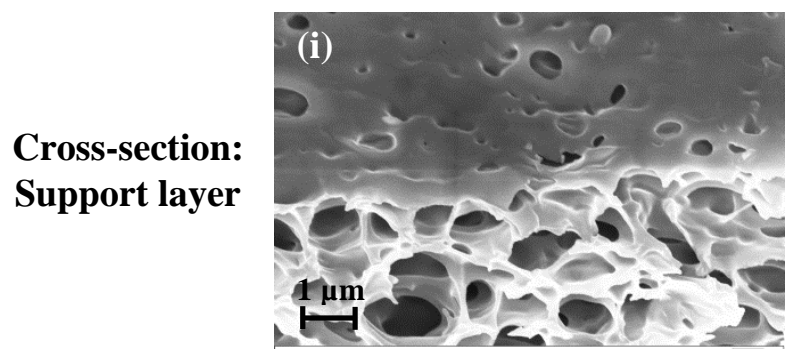

After fouling
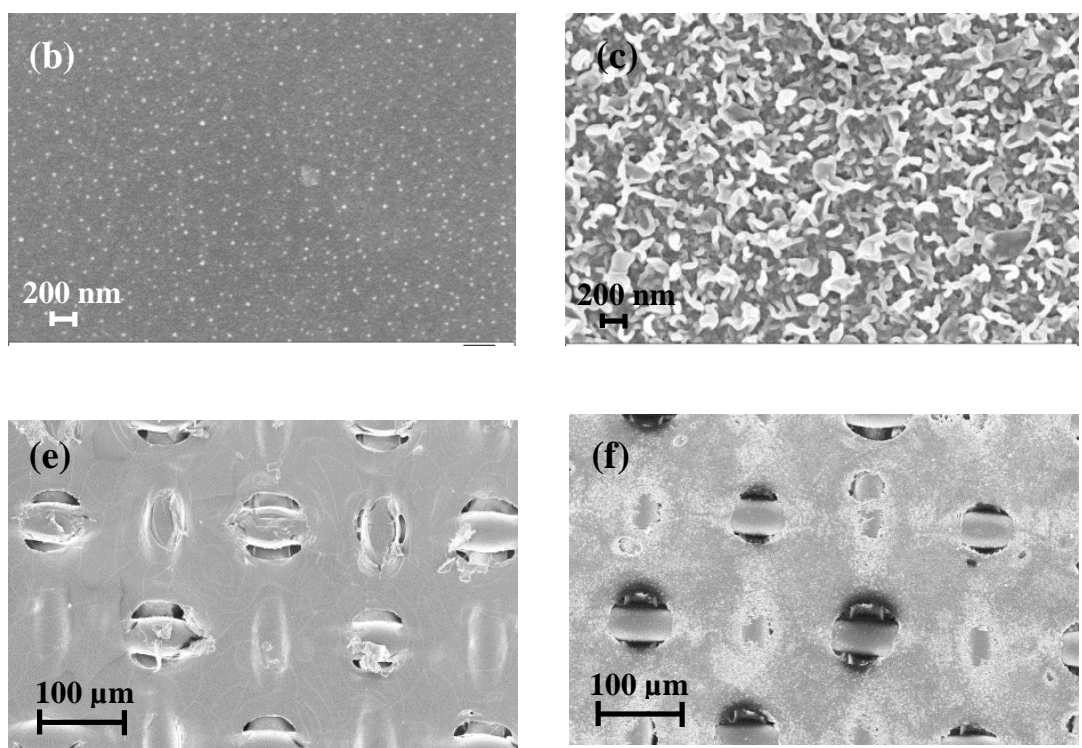

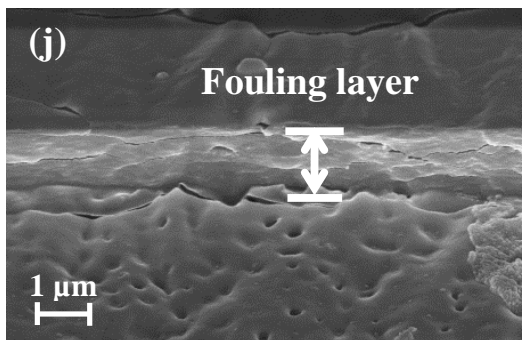

Figure 7: SEM micrographs of pristine, fouled and cleaned TFC membranes; (a-c) top surface, (d-f) bottom surface, and (g-j) cross-sectional micrographs. Figures (e) and (j) show the fouling layer on the TFC support surface which covered $\sim 2-5 \%$ of the fouled membrane surface. 


\subsubsection{Fouling Layer Characteristics}

\subsubsection{Fouling Density}

Previous studies have suggested that fouling in FO is more reversible than RO due to a less compact fouling layer formed as a consequence of osmotic pressure used as the driving force instead of hydraulic pressure $[4,6,7,37]$. These inferences however, were based on membrane performance results without being supplemented by any quantitative analysis. The relationship between the fouling layer properties formed in FO in relation to hydrodynamic conditions, which are known to have an effect on fouling, have not yet been explicitly investigated. In this section, the fouling layer density was quantified using a method described in Section 2.6.3 and any correlation between fouling density and local cross-flow velocity at different radial positions in the FO cell was observed (Figure 8). The local cross-flow velocities were obtained from CFD simulations using the cell geometry and specified parameters representing hydrodynamic conditions in the cell. A schematic of the velocity field and magnitude at a height of $1 \mathrm{~mm}$ from the membrane surface (i.e. equivalent to the maximum thickness of the hydrated fouling layer) is shown in Figure S-8 of the ESI.

Figure 8 shows the variation in fouling density with cross-flow velocity across five radial positions in the cell, starting with $0.5 \mathrm{~cm}$ from the centre of the membrane and radiating outwards $2.5 \mathrm{~cm}$ towards the edge. The cross-flow velocity decreased from the centre to the edge of the cell as shown in Figure S-9 of the ESI. Although we expected to see a corresponding change in fouling density with crossflow velocity, a clear correlation was not observable. Instead, a comparable range of fouling density between 30-60 mg.cm ${ }^{-3}$ was observed for the CTA and TFC membranes at $1.0 \mathrm{~cm}$ to $2.5 \mathrm{~cm}$ radial distance across the cell. The low variation in cross-flow velocity may be a reason for its insignificant effect on density, since higher cross-flow velocities have had a greater effect on fouling density [24]. The comparable range of fouling density observed on the membranes studied implies that there is not a strong correlation between foulant-membrane interaction and fouling density, and the greater extent of fouling on the TFC top surface is likely attributed to other factors. Fouling density measurements 
were not performed for the TFC membrane in PRO mode as there was no fouling layer visible on the membrane surface.
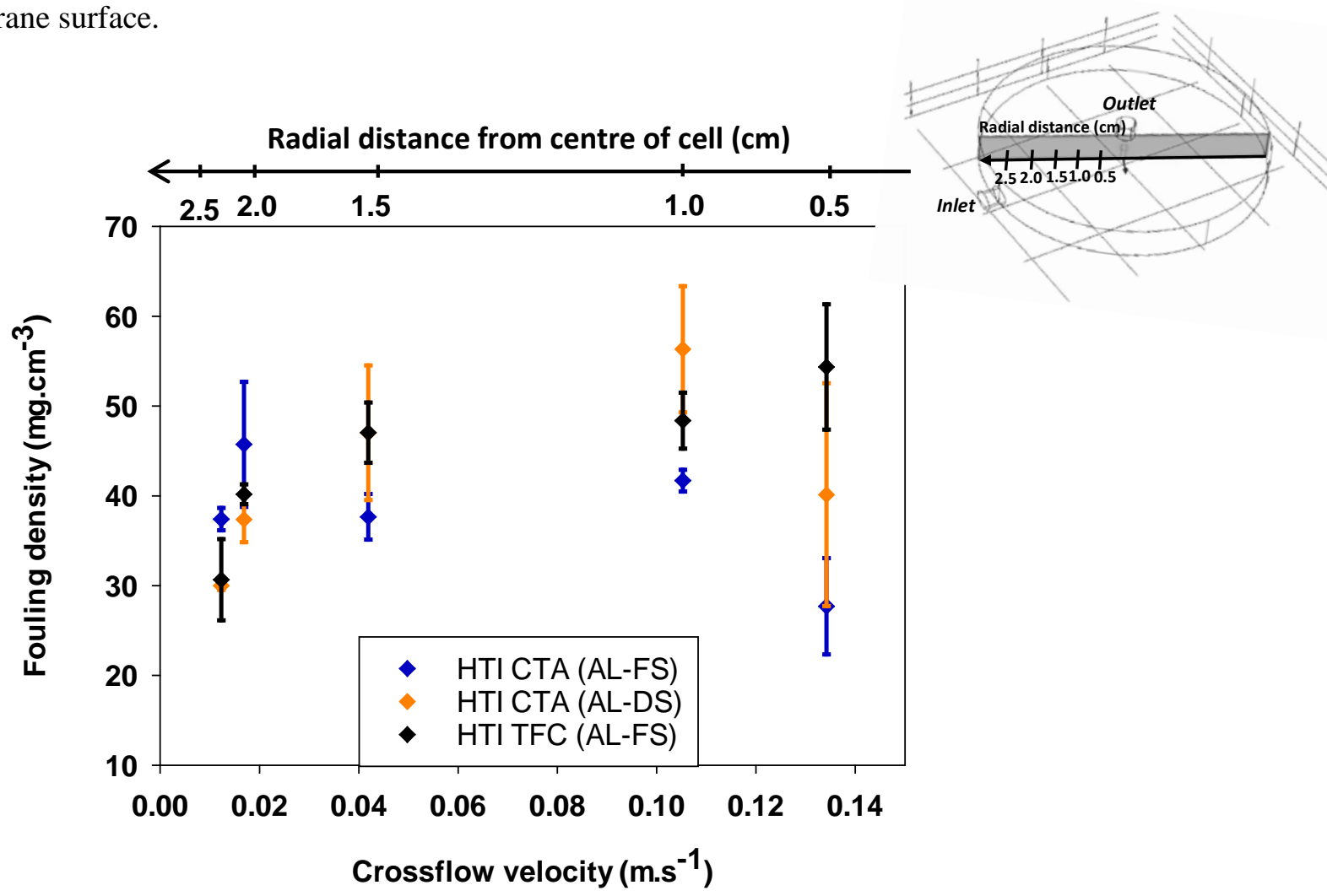

Figure 8: Effect of membrane type and orientation on fouling density at different cross-flow velocities. Membranes were oriented in the active layer facing feed solution (AL-FS) and active layer facing draw solution (AL-DS).

\subsubsection{Specific Mass of Foulant Adsorbed}

Table 4 shows the total mass of alginate adsorbed per unit volume of permeate produced following the fouling experiments. It was observed that the TFC membrane in PRO mode which displayed the highest flux decline, exhibited the greatest adsorbed mass of foulant per volume of filtrate. However, despite its greater extent of fouling compared to the CTA membrane (Figure 5), the TFC membrane in FO mode displayed the lowest amount of alginate adsorbed per litre of permeate. This suggests that fouling of the TFC membrane in FO mode is more significantly influenced by other factors such as membrane surface properties which will be explored further in the following sections. 


\begin{tabular}{|c|c|c|}
\hline $\begin{array}{c}\text { Membrane } \\
\text { orientation }\end{array}$ & Membrane type & $\begin{array}{c}\text { Specific mass of alginate } \\
\text { adsorbed }\left(\mathbf{m g . ~}^{\mathbf{- 1}} \text { ) }\right.\end{array}$ \\
\hline \multirow{2}{*}{ FO mode } & CTA & $75.1 \pm 0.3$ \\
\cline { 2 - 3 } & TFC & $68.0 \pm 4.2$ \\
\hline \multirow{2}{*}{ PRO mode } & CTA & $84.2 \pm 2.2$ \\
\cline { 2 - 3 } & TFC & $105.1 \pm 6.6$ \\
\hline
\end{tabular}

Table 4: Effect of membrane type and orientation on specific mass of alginate adsorbed during fouling.

\subsubsection{Membrane Surface Properties}

\subsubsection{Surface Roughness}

To elucidate the effect of surface roughness on the fouling behaviour of the membranes studied, AFM measurements were performed to quantify surface roughness. AFM images of the surfaces studied along with their root mean square (RMS) roughness values are shown in Figure 9. The procedure used to ensure roughness properties of the different surfaces were compared on the same basis, is explained in Section 3.0 of the ESI.

The TFC active layer has a uniform ridge-and-valley structure across its entire surface (Figure 9 (a)) with an RMS of $57.4 \mathrm{~nm}$, indicating a greater roughness than the CTA membrane, RMS= $3.8 \mathrm{~nm}$. In actuality, its surface roughness could be even higher as the value measured by AFM across the scanned area is limited by the probe's accessibility to the underlying polyamide surface (Figure S-11 of the ESI). The TFC's rougher surface could explain the fouling behaviour results (Figure 5 (a)) whereby the extent of fouling was slightly greater on the TFC membrane compared to CTA in FO mode, as observed in the greater deviation in membrane permeance from the baseline during fouling. Moreover, the foulant used in this study, calcium alginate, has a measured average hydrodynamic diameter of $15 \pm 3 \mathrm{~nm}$ in the feed solution (Figure S-12 of the ESI). This means that on the nano scale, calcium alginate molecules are small enough to enter the valley depths of the TFC active layer and cause valley clogging, given that the peak-to-peak distance of the TFC active layer ranges from $20 \mathrm{~nm}$ 
to distances greater than $200 \mathrm{~nm}$ (Figure S-7 (a) of the ESI). Additionally, the peak-to-valley depth of the TFC PA layer reduces shear effects within the ridge-and-valley structure and enhances valley clogging. It is postulated that the calcium alginate molecules will first aggregate in the valleys of the TFC membrane before forming a continuous gel layer across the membrane surface, as a result of the stable "egg-box" structure formed by calcium alginate links (Figure S-6 (c) of the ESI). This renders the TFC active surface more prone to fouling by calcium alginate. A study simulating the effect of membrane surface roughness on colloid-membrane Derjaguin-Landau-Verwey-Overbeek (DLVO) interactions [38] suggested that as particles approach closer to the membrane surface, they have a high probability of getting trapped in the valleys of the rough membrane surface. Once trapped, the particle may be shielded from cross-flow shear by the large positive asperities, resulting in enhanced initial particle deposition. The presence of an attractive energy well due to van der Waals forces of attraction surrounding each protruding asperity suggests a complex interaction between colloidal and physical (steric) interactions, which are absent on smooth surfaces [38].

The smoother active surface of the CTA membrane results in alginate aggregating and forming a continuous gel layer on the membrane surface (Figure S-6 (a) of the ESI). The comparable fouling behaviour on the active and support surfaces of the CTA membrane (Figure 5 (a) and (b)), can be explained partly by the similar surface roughness of both surfaces. The average RMS of the CTA support surface is $3.6 \mathrm{~nm}$ which is comparable to the active surface, RMS $=3.8 \mathrm{~nm}$. This is not surprising, given the homogeneity of the surfaces, as demonstrated in Section 3.1.2. Once an initial foulant layer is deposited, the effects of surface roughness become less prominent as subsequent fouling becomes more influenced by foulant-foulant interaction.

Although the TFC support surface $(\mathrm{RMS}=25.3 \mathrm{~nm}$ ) is smoother than the active surface (RMS = 57.4 $\mathrm{nm}$ ), flux decline due to fouling is significantly greater in PRO mode due to pore clogging. Therefore, surface roughness is not a contributing factor to fouling in this orientation, which is more a function of the porous support structure. 
(a) TFC Active Layer

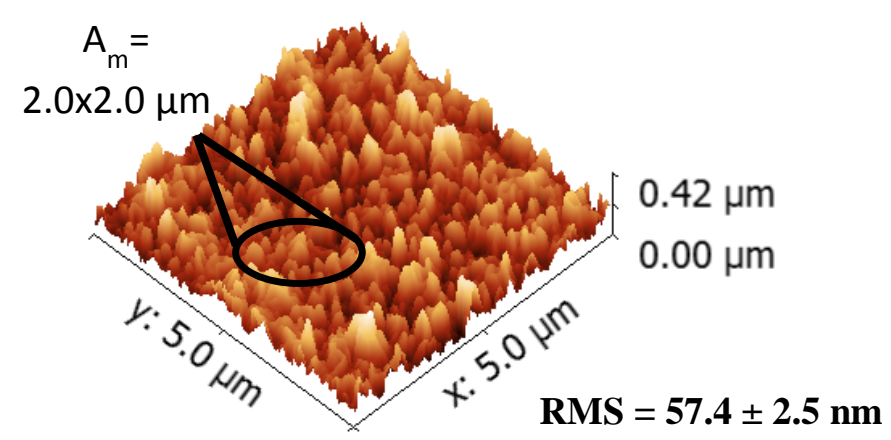

(b) TFC Support Layer

$A_{m}=$

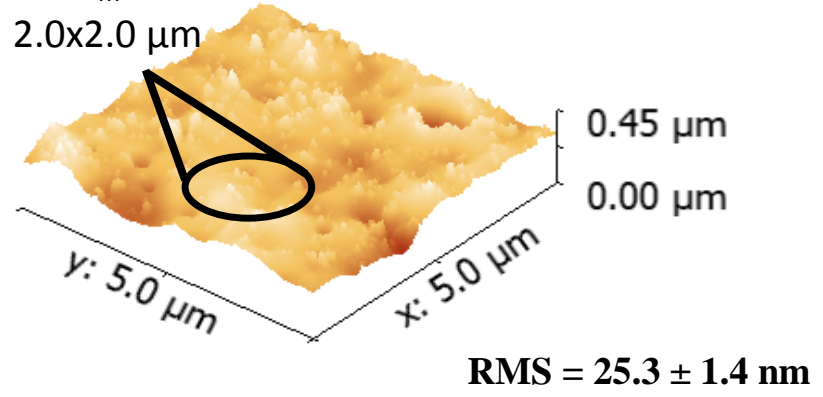

(c) CTA Active Layer

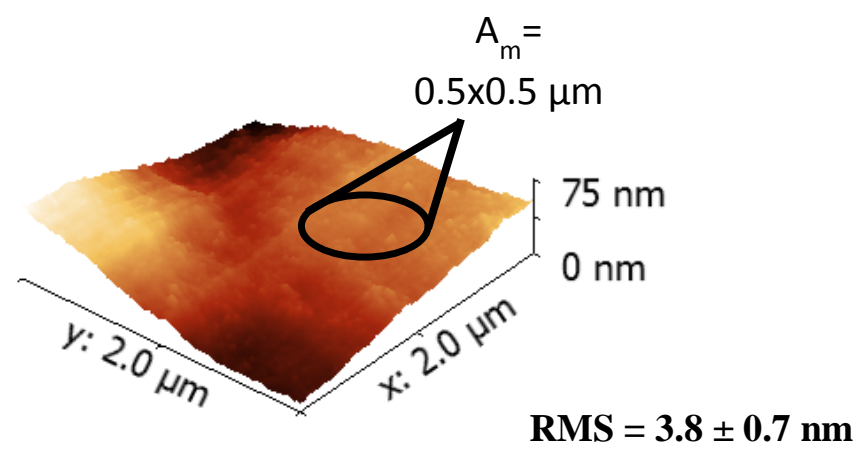

(d) CTA Support Layer

$A_{m}=$

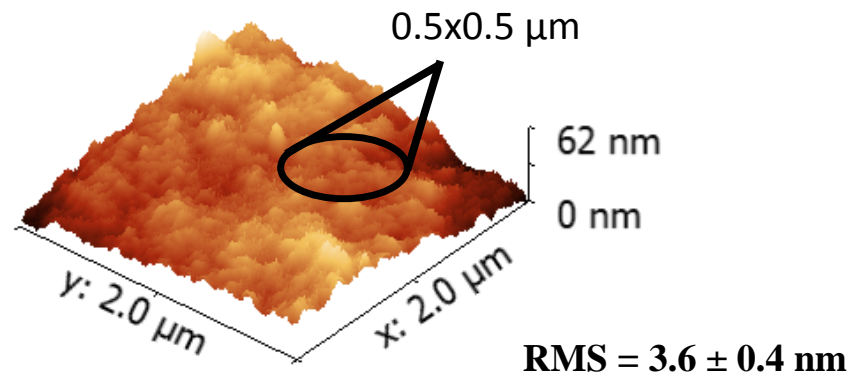

Figure 9: AFM images of the active and support layer surfaces of HTI-TFC (a,b) and CTA (c,d) membranes. For the TFC membrane, four locations each measuring $2 \times 2 \mu \mathrm{m}$ in size were selected from the $5 \mathrm{x} 5 \mu \mathrm{m}$ scan size. For the CTA membrane, four locations each measuring $0.5 \mathrm{x} 0.5 \mu \mathrm{m}$ in size were selected from the $2 \times 2 \mu \mathrm{m}$ scan size. An average value for roughness was taken from the four measurements.

\subsubsection{Surface Hydrophilicity}

The CTA active and support layers had similar contact angles of $63.3 \pm 1^{\circ}$ and $67.5 \pm 2{ }^{\circ}$, respectively. Amongst other factors, the similarity in surface hydrophilicity may also contribute to the comparable fouling behaviour observed on the CTA membrane (Figure 5 (a) and (b)). The TFC active layer has a lower contact angle of $27.4 \pm 1^{\circ}$, suggesting that it is more hydrophilic than CTA and other high performance FO membranes [39]. However, the improved hydrophilicity of the TFC active layer is not reflected in its propensity for fouling which is greater than the CTA membrane (Figure 5 (a)). This 
suggests that surface roughness had a greater influence on alginate fouling than membrane hydrophilicity. The contact angle of the TFC support layer was not measurable as the water droplet was absorbed during measurement by the porous support.

\subsubsection{Surface Charge}

The electrostatic interaction between the foulant and membrane surface at different $\mathrm{pH}$ can be described using zeta potential. At the ambient $\mathrm{pH}$ of the fouling solution i.e. $\mathrm{pH}$ 6.8, the carboxylic acid groups of sodium alginate alone would have been almost completely deprotonated, leading to an increase in electrostatic repulsion. However, the complexation of alginate with divalent ions such as $\mathrm{Ca}^{2+}$ results in charge minimisation and intermolecular bridging, causing agglomeration of the alginate molecules and forming a structured gel upon deposition on the membrane surface [40].

At the fouling solution $\mathrm{pH}(\mathrm{pH}$ 6.8), the surface charge of calcium alginate was $-20 \pm 2 \mathrm{mV}$, resulting in electrostatic repulsion between the negatively charged foulant and membrane surface. Despite the repulsive forces, foulant deposition occurred due to interactions such as hydrogen bonding and van der Waals forces of attraction in the short range $(0-0.5 \mathrm{~nm})$, ionic bonds in the long range $(0.5-2 \mathrm{~nm})$ and hydrophobic interactions [41, 42]. Ionic bonds are likely formed with the membrane surface despite repulsive forces as they form at distances larger than the Debye length, where the repulsive energy is most prominent. Additionally, higher $\mathrm{NaCl}$ concentrations in the actual fouling feed solution may result in the compression of the electrochemical double layer, resulting in a reduction of the repulsive energy barrier [43] and an increase in net attractive forces. The soft and flexible nature of the calcium alginate gel provides a further explanation for foulant deposition as it is continuously adsorbed on the membrane surface owing to a gain in conformational entropy.

From Figure 10 (a), it can be observed that the CTA surface was more negatively charged than TFC in the presence of $\mathrm{Na}^{+}$and $\mathrm{Ca}^{2+}$, resulting in greater electrostatic repulsion with alginate. This could be a contributing factor towards its lower fouling propensity compared to TFC in FO mode as seen in Figure 5 (a). The zeta potential of the CTA top and bottom surfaces (Figure 10 (b)) are very similar, 
owing to the same polymeric material used, which corresponds well to the comparable fouling propensities of these surfaces (Figure 5 (a) and (b)).

Following the adsorption of foulant onto the membrane surface, subsequent fouling is likely governed by the free energy of cohesion between approaching alginate molecules and those already deposited on the membrane surface, contributing to the onset of foulant-foulant interaction [44]. It can be seen that once the foulant layer had been adsorbed onto the membrane surface, the zeta potential of all the surfaces were comparable at the ambient $\mathrm{pH}$ of the fouling solution ( $\mathrm{pH}$ 6.8), i.e. they approached the surface charge of calcium alginate $(-20 \pm 2 \mathrm{mV})$. This indicates that a foulant layer had been adsorbed onto the membrane surface. Further, the similar surface charge post-foulant adhesion, infers that fouling on these membranes are governed primarily by the initial interaction between the foulant and membrane surface.

(a)
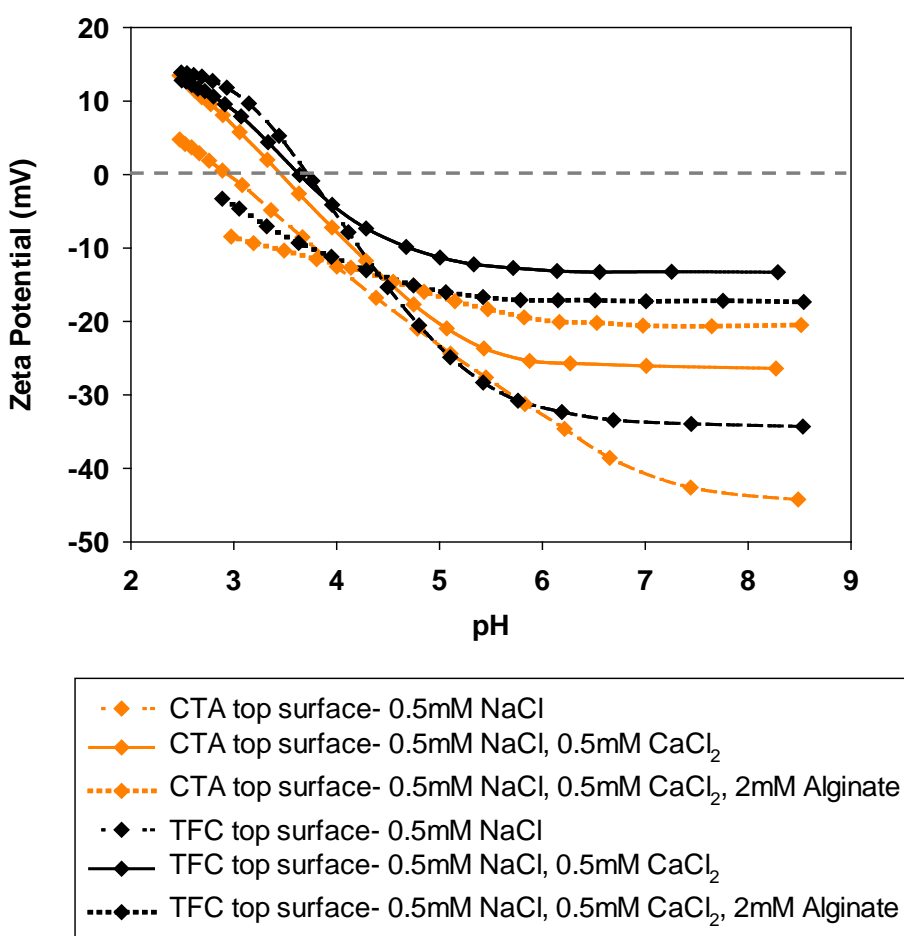
(b)

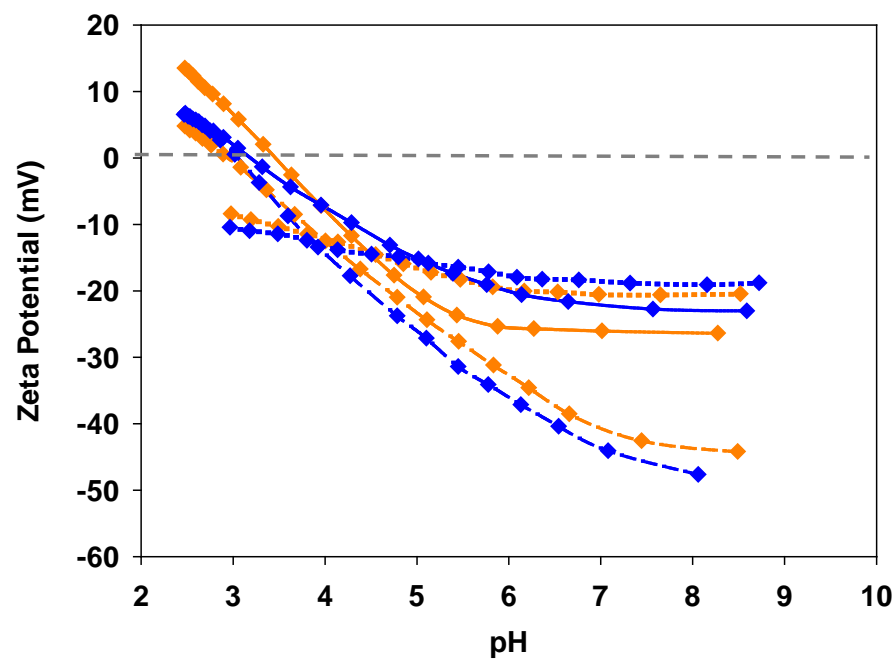

- CTA top surface- $0.5 \mathrm{mM} \mathrm{NaCl}$

$\leadsto$ CTA top surface- $0.5 \mathrm{mM} \mathrm{NaCl}, 0.5 \mathrm{mM} \mathrm{CaCl}_{2}$

- CTA top surface- $0.5 \mathrm{mM} \mathrm{NaCl}, 0.5 \mathrm{mM} \mathrm{CaCl}_{2}, 2 \mathrm{mM}$ Alginate

- CTA bottom surface- $0.5 \mathrm{mM} \mathrm{NaCl}$

$\longrightarrow$ CTA bottom surface- $0.5 \mathrm{mM} \mathrm{NaCl}, 0.5 \mathrm{mM} \mathrm{CaCl}_{2}$

- CTA bottom surface- $0.5 \mathrm{mM} \mathrm{NaCl}, 0.5 \mathrm{mM} \mathrm{CaCl}_{2}, 2 \mathrm{mM}$ Alginate

Figure 10: Zeta potential on (a) CTA and TFC top surface; (b) CTA top and bottom surfaces, as a function of $\mathrm{pH}$ with solutions representing baseline conditions $(0.5 \mathrm{mM} \mathrm{NaCl})$, feed solution before (0.5 mM NaCl, $\left.0.5 \mathrm{mM} \mathrm{CaCl}{ }_{2}\right)$ and after foulant addition (0.5 mM NaCl, $0.5 \mathrm{mM} \mathrm{CaCl}$, 2.0 mM Alginate).

\subsubsection{Surface Chemical Heterogeneity}

A study by Kim et al. has shown that surface chemical heterogeneity influences foulant deposition by introducing a higher area of favourable sites or patches for foulant adhesion [45]. The extent of chemical heterogeneity is related to the distribution of the atomic (or molecular) species and functional groups present on the membrane surface, which in turn affect surface composition and interactions between foulant and the surface.

The XPS results (Table 3) provide a good indication of the various functional groups present on the membrane surface which contribute to surface chemical heterogeneity. These results illustrate the presence of $\mathrm{O}-\mathrm{C}=\mathrm{O}$ groups on the TFC membrane surface (5.5 \% of the $\mathrm{C} 1 \mathrm{~s}$ spectra) which is 
characteristic of highly polar carboxylate groups available for ionic bonding with the foulant, thus enhancing the number of favourable sites for foulant adhesion. For the CTA membrane, the $\mathrm{O}-\mathrm{C}=\mathrm{O}$ group ( $24.9 \%$ of the C1s spectra) is associated with the acetate functional group and hence, exhibits a weaker ion-dipole interaction with the foulant at the fouling solution $\mathrm{pH}$ of 6.8. This further explains the greater fouling propensity on the TFC active surface compared to CTA. Additionally, the presence of excess unreacted amine groups on the TFC membrane ( $5 \%$ of the N1s spectra) could generate favourable sites for foulant adhesion via electrostatic forces of attraction between the positively charged sites and negatively charged foulant. A molecular dynamic study on the interaction between a hydrated polyamide membrane and calcium alginate [42] showed that the probability of forming long-range $(0.5-2 \mathrm{~nm})$ ionic bridges between the negatively charged carboxylate ions on the alginate and the PA surface is over $80 \%$. The rest of the binding sites involve direct PA-alginate interactions without metal ions. These include short-range $(0-0.5 \mathrm{~nm})$ hydrogen bonds between the hydroxyl group of the alginate molecule and carboxylate group of the PA layer, van der Waals forces of attraction and hydrophobic interactions.

\subsection{Cleaning and Fouling Reversibility}

Physical and chemical cleaning is a significant step in any membrane process to minimise fouling and extend the performance lifetime of a membrane. Investigating the cleaning behaviour of FO membranes enables the quantification of fouling reversibility, which subsequently provides information on the fouling propensity of these membranes.

The results for normalised flux decline after fouling and flux recovery after cleaning are presented in Figure 11. The CTA membrane in FO and PRO mode had high cleaning efficiencies and flux recoveries of $96 \%$ and $95 \%$ respectively. These results suggest a physical removal of the fouling layer as a result of the shear force generated by increased cross-flow. They also suggest that fouling by calcium alginate was mainly a result of adsorption on the active and support surfaces of the CTA membrane rather than a pore clogging mechanism. 
The flux recovery of the TFC membrane after cleaning in FO mode was $85 \%$, i.e. $10 \%$ lower compared to CTA. This suggests a greater adhesion of foulant on the TFC active surface, which can be attributed to factors such as surface roughness, surface charge, surface chemical heterogeneity and hydrodynamic effects i.e. the lack of shear in the ridge-and-valley structure of the PA layer, rendering cross-flow less effective on foulant removal in this region. A previous study [42] suggested that due to the flexible gel-like behaviour of calcium alginate, the alginate gel may tend to adapt to the morphology of the polyamide surface, thus increasing the contact area with the membrane. The packing density of the gel is distance dependent from the membrane surface, with a more compact gel formed adjacent to the surface due to the strong attraction between the foulant and the membrane. As suggested by this study, this “distance-dependent” density contributed to the weaker effects of crossflow cleaning in removing the alginate from the PA surface.

Cleaning with cross-flow was not effective on the TFC membrane in PRO mode due to pore clogging. The reduced effects of cross-flow in the porous support renders shear force ineffective as a cleaning mechanism in this orientation with a flux recovery of only $37 \%$. Hence, a more effective physical cleaning method had to be adopted which is presented in the following section.

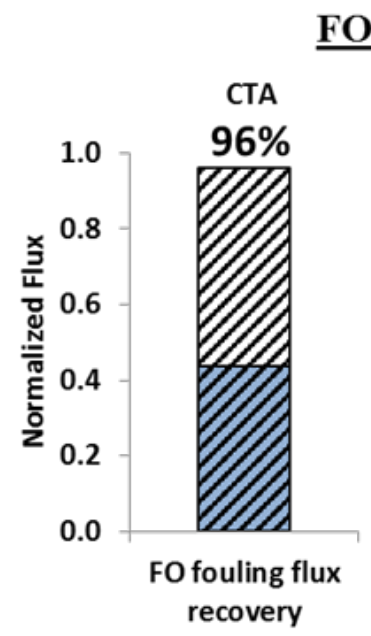

FO mode

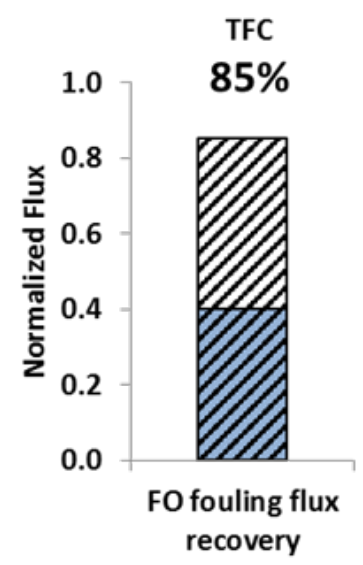

PRO mode
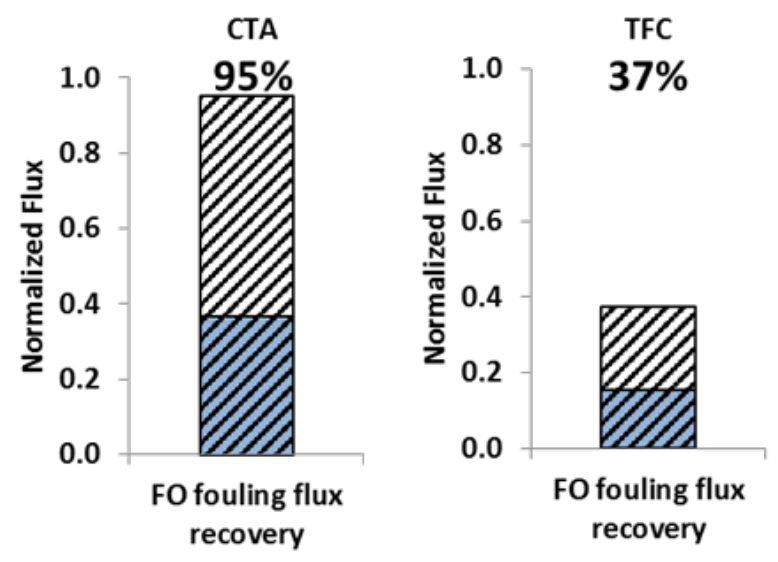

Flux after fouling Flux after cleaning

Figure 11: Flux recovery of fouled CTA and TFC membranes in FO and PRO mode, after cleaning with

DI water at $60 \mathrm{~L} . h^{-1}$ for 15 minutes. Flux after fouling is normalised by the initial flux of the fouling experiments, while flux after cleaning is normalised by the initial baseline flux of a pristine membrane. 


\subsubsection{Relating TFC Membrane Structural Properties with Fouling and Cleaning Behaviour in PRO mode}

As illustrated in the previous section, physical cleaning with increased cross-flow in PRO mode was ineffective in removing the foulant layer deposited in the porous support of the TFC membrane. Hence, backwashing was employed as an alternative cleaning method to improve flux recovery of the fouled membrane. Figure 12 (a-d) shows four fouling tests, each conducted over a period of 2 h, 5 h, $16 \mathrm{~h}$ and $27 \mathrm{~h}$, respectively. Backwashing was performed after each fouling experiment. Results indicate that the amount of alginate accumulated in the porous support increased significantly in the first 10 hours of fouling and approached a steady state thereafter (Figure 12 (e)). The higher initial fluxes coupled with lack of shear in the porous support induced greater initial fouling. Interestingly, the onset of steady state flux observed after 10 hours of fouling (Figure 12 (d)) corresponds to the insignificant increase in the amount of foulant adsorbed within the support layer between $10 \mathrm{~h}$ and 27 h (Figure $12(\mathrm{e})$ ), suggesting that further fouling of the membrane had occurred minimally during this period.

The increase in the amount of foulant adsorbed over time had an effect on the degree of backwash flux required for fouling reversibility. As observed in the $2 \mathrm{~h}$ and $5 \mathrm{~h}$ fouling experiments, the efficiency of backwashing using the original fouling FS and DI water on the draw side decreased with time as more foulant was adsorbed within the porous support layer. This is quantitatively shown by the $87 \%$ flux recovery achieved after the $2 \mathrm{~h}$ fouling test but only $65 \%$ recovered after 5 hours of fouling under the same cleaning conditions. However, when backwashing was conducted with $1 \mathrm{M}$ $\mathrm{NaCl}$ as the FS, a higher backwash flux was achieved, resulting in almost $100 \%$ flux recovery. Using the same cleaning solution conditions, similar flux recoveries were observed for membranes fouled over 16 and 27 hours. For the membrane fouled over 27 hours, backwashing was conducted at a higher cross-flow rate of $60 \mathrm{~L} \cdot \mathrm{h}^{-1}$ to ensure that foulant removed from the porous support was effectively cleaned off the membrane surface. 
(a)

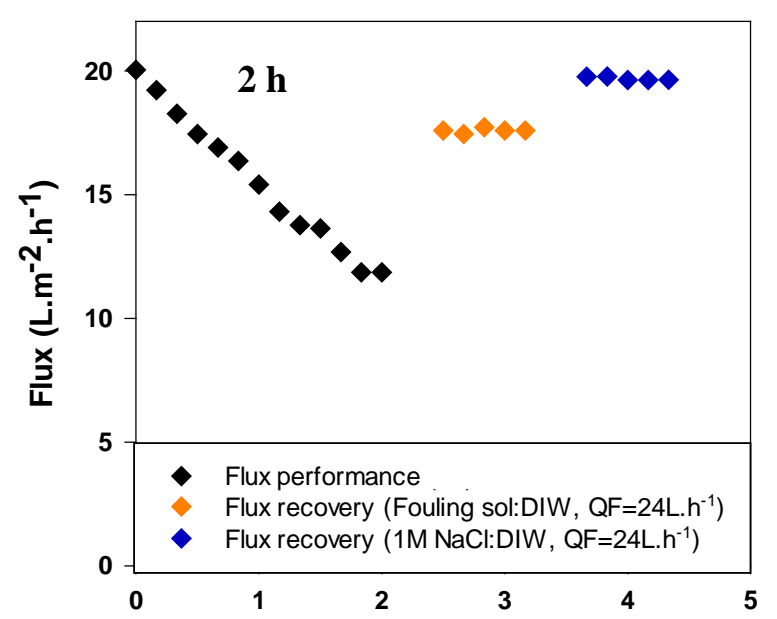

(c)

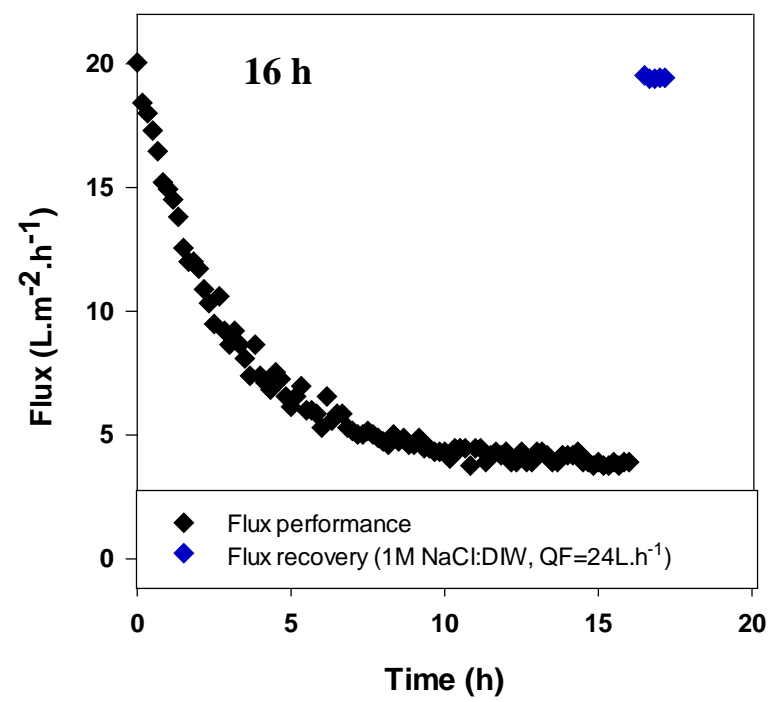

(b)

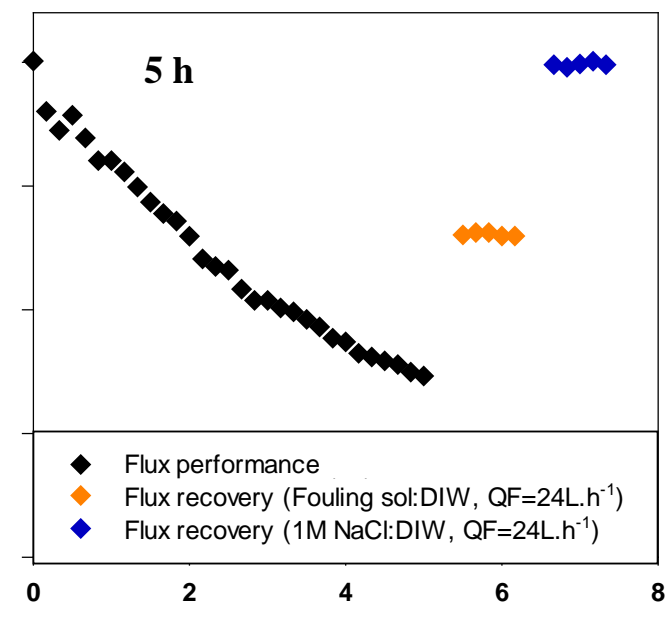

(d)

Time (h)

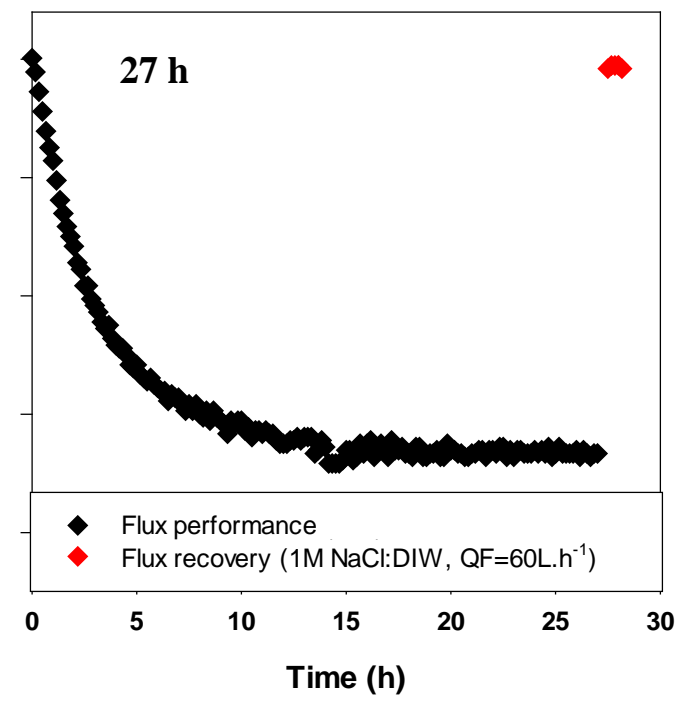

(e)

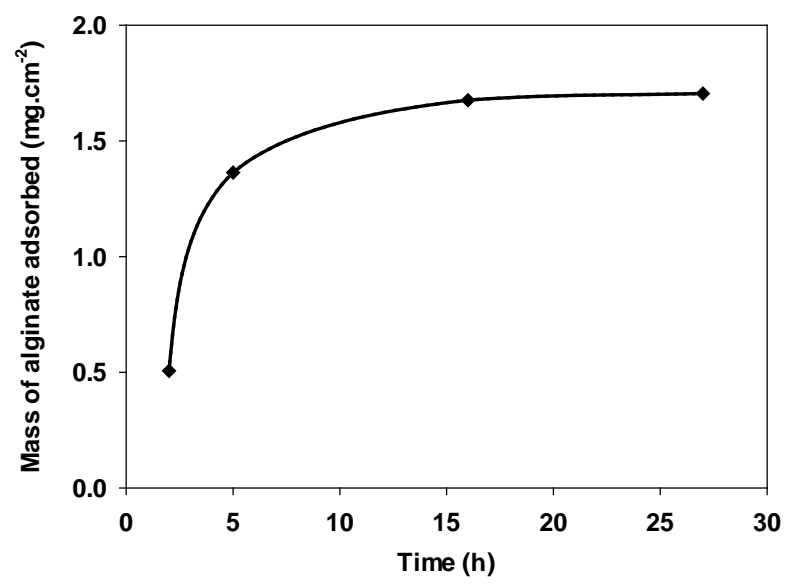

Figure 12: (a-d) Fouling behaviour and flux recovery of the HTI-TFC membrane in PRO mode under various cleaning conditions at $2 \mathrm{~h}, 5 \mathrm{~h}, 16 \mathrm{~h}$ and $27 \mathrm{~h}$, and (e) Specific mass of alginate adsorbed within the porous support at 2 h, 5 h, 16 $h$ and $27 \mathrm{~h}$ of fouling in PRO mode. 


\subsection{Conclusion}

Two FO membranes with varying chemical and structural properties were studied. The HTI-TFC membrane was found to exhibit superior permeance and rejection performance compared to the HTICTA due to its favourable surface and structural properties, implying that thin film composite membranes with ideal structures are a step forward in the development of high performance FO membranes. However, this observation does not account for performance under fouling conditions.

The HTI-TFC membrane performed poorly compared to HTI-CTA under fouling conditions in the presence of calcium alginate, in both orientations. The TFC active layer had a higher surface roughness and a lower negative charge resulting in greater fouling propensity in FO mode. Additionally, the presence of carboxylate functional groups enhanced the number of favourable sites for foulant adhesion through ionic bonding. Surface hydrophilicity and fouling density did not have a significant effect on the fouling propensity of these membranes. Comparable fouling densities on the CTA and TFC active surfaces suggest that stronger interactions between the foulant and the TFC active surface do not necessarily lead to increased fouling density, which is likely a greater function of applied hydraulic forces such as in the case of RO.

In PRO mode, membrane surface properties played a less significant role compared to membrane structural properties in determining fouling behaviour. The highly asymmetric and open structure of the TFC support caused severe fouling as a result of pore clogging, exacerbated by the reduced effects of cross-flow within the porous support. Alginate fouling occurred as a surface phenomenon on the support layer of the CTA membrane due to its dense structure coupled with the highly cross-linked gel network formed by calcium alginate upon aggregation. This implies that fouling mechanisms on FO membranes are specific to the foulant size and aggregation structure in relation to the support pore size. Hence, FO supports of different structures and pore sizes may be selected for use depending on the type of foulant present in the feed water, in order to achieve a balance between superior flux performance and reduced fouling propensity in PRO mode. If smaller and weakly aggregating 
foulants are used, a trade-off between membrane performance and fouling mitigation will occur as the use of integrally asymmetric or double-skinned membranes with improved fouling resistance will be limited by their denser structures and enhanced ICP effects. Unless significant improvement is made to improve their structure and reduce ICP in these membranes, fouling mitigation will be at the expense of flux performance.

Due to the lower fouling propensity of the CTA membrane, physical cleaning with DI water and an increased cross-flow velocity was sufficient to achieve an almost complete flux recovery. The TFC membrane however, had poorer fouling reversibility and required backflushing with a sufficiently high driving force in PRO mode to achieve comparable flux recoveries to CTA.

The fouling results imply that the successful application of FO would involve a diversification of membrane designs tailored to the type of feed solution used. The compromise between membrane performance and membrane fouling propensity would have to be addressed by innovating improved structural properties of FO membranes such that ICP effects are mitigated. Alternatively, the successful reengineering of the polyamide surface on a highly open support can result in superior performance and minimal fouling in FO mode, which would be highly beneficial for treatment of raw feeds with high fouling potential.

Despite different mechanisms of fouling and quantities of foulant adsorbed on the FO membranes, FO is undoubtedly a resilient process with high cleaning efficiencies and fouling reversibility. Hence, although most FO hybrid processes may not be competitive from an energetic perspective compared to RO, their high fouling reversibility may reduce or eliminate the need for chemical cleaning and pretreatment, which makes them an attractive prospect for use with challenging feeds. 


\section{Acknowledgements}

We would to acknowledge the support provided by the Department of Chemical Engineering, Imperial College London, and the CIMB Regional Scholarship Award awarded by CIMB Foundation (795634-H) to N.M.M.

\section{Author Contributions Statement}

N.M.M. designed and performed experiments, analysed data and wrote the paper. P.M. supervised the code writing for Matlab and running models for data analysis. H.A.M. performed zeta potential measurements. B.G. performed Computational Fluid Dynamics (CFD) simulation. S.K. performed deconvolution of the XPS spectra. A.B. supervised zeta potential measurements. A.G.L. supervised the project. 


\section{References:}

1. Shaffer, D.L., et al., Forward osmosis: Where are we now? Desalination, 2015. 356: p. 271284.

2. McGovern, R.K. and J.H. Lienhard, On the potential of forward osmosis to energetically outperform reverse osmosis desalination. Journal of Membrane Science, 2014. 469: p. 245250.

3. Mazlan, N.M.P., D.; Livingston, A.G., Energy Consumption for Desalination - A Comparison of Forward Osmosis with Reverse Osmosis, and the Potential for Perfect Membranes. Desalination, 2015. 377: p. 138-151.

4. Mi, B.X. and M. Elimelech, Organic fouling of forward osmosis membranes: Fouling reversibility and cleaning without chemical reagents. Journal of Membrane Science, 2010. 348(1-2): p. 337-345.

5. $\mathrm{Mi}, \mathrm{B}$. and M. Elimelech, Chemical and physical aspects of organic fouling of forward osmosis membranes. Journal of Membrane Science, 2008. 320(1-2): p. 292-302.

6. Achilli, A., et al., The forward osmosis membrane bioreactor: A low fouling alternative to MBR processes. Desalination, 2009. 239(1-3): p. 10-21.

7. Lee, S., et al., Comparison of fouling behavior in forward osmosis (FO) and reverse osmosis (RO). Journal of Membrane Science, 2010. 365(1-2): p. 34-39.

8. Peter Nasr, H.S., Forward osmosis: an alternative sustainable technology and potential applications in water industry. Clean Techn Environ Policy, 2015.

9. Liu, Y.L. and B.X. Mi, Combined fouling of forward osmosis membranes: Synergistic foulant interaction and direct observation of fouling layer formation. Journal of Membrane Science, 2012. 407: p. 136-144.

10. Cornelissen, E.R., et al., Membrane fouling and process performance of forward osmosis membranes on activated sludge. Journal of Membrane Science, 2008. 319(1-2): p. 158-168.

11. Holloway, R.W., et al., Forward osmosis for concentration of anaerobic digester centrate. Water Research, 2007. 41(17): p. 4005-4014.

12. She, Q.H., et al., Membrane fouling in osmotically driven membrane processes: A review. Journal of Membrane Science, 2016. 499: p. 201-233.

13. Ren, J. and J.R. McCutcheon, A new commercial thin film composite membrane for forward osmosis. Desalination, 2014. 343: p. 187-193.

14. Nguyen, T.P.N., et al., Comparison of integrally asymmetric and thin film composite structures for a desirable fashion of forward osmosis membranes. Journal of Membrane Science, 2015. 495: p. 457-470.

15. Xie, M., et al., Role of pressure in organic fouling in forward osmosis and reverse osmosis. Journal of Membrane Science, 2015. 493: p. 748-754.

16. (HTI), H.T.I. HTI'S New Thin Film Forward Osmosis Membrane in Production. 2012; Available from: $\quad$ http://www.htiwater.com/news/press-room/content/2012/press-HTIHTIThinFilmMembrane042512.pdf.

17. Desalination.com. TFC FO elements now available. 2012; Available from: http://www.desalination.com/wdr/48/17/tfc-fo-elements-now-available.

18. Sahebi, S., et al., Effect of sulphonated polyethersulfone substrate for thin film composite forward osmosis membrane. Desalination, 2016. 389: p. 129-136.

19. Huang, L.W., J.T. Arena, and J.R. McCutcheon, Surface modified PVDF nanofiber supported thin film composite membranes for forward osmosis. Journal of Membrane Science, 2016. 499: p. 352-360.

20. Stillman, D., L. Krupp, and Y.H. La, Mesh-reinforced thin film composite membranes for forward osmosis applications: The structure-performance relationship. Journal of Membrane Science, 2014. 468: p. 308-316. 
21. Gu, Y.S., et al., Organic fouling of thin-film composite polyamide and cellulose triacetate forward osmosis membranes by oppositely charged macromolecules. Water Research, 2013. 47(5): p. 1867-1874.

22. Cath, T.Y., Standard Methodology for Evaluating Membrane Performance in Osmotically Driven Membrane Processes Desalination (to be confirmed), 2012.

23. Characklis, W.G. and K.C. Marshall, Biofilms. Wiley series in ecological and applied microbiology. 1990, New York: Wiley. xvii, 796 p.

24. Choi, H., et al., Influence of cross-flow velocity on membrane performance during filtration of biological suspension. Journal of Membrane Science, 2005. 248(1-2): p. 189-199.

25. McCutcheon, J.R. and M. Elimelech, Influence of concentrative and dilutive internal concentration polarization on flux behavior in forward osmosis. Journal of Membrane Science, 2006. 284(1-2): p. 237-247.

26. McCutcheon, J.R. and M. Elimelech, Modeling water flux in forward osmosis: Implications for improved membrane design. Aiche Journal, 2007. 53(7): p. 1736-1744.

27. Peeva, L.G., et al., Effect of concentration polarisation and osmotic pressure on flux in organic solvent nanofiltration. Journal of Membrane Science, 2004. 236(1): p. 121-136.

28. McCutcheon, J.R., R.L. McGinnis, and M. Elimelech, Desalination by ammonia-carbon dioxide forward osmosis: Influence of draw and feed solution concentrations on process performance. Journal of Membrane Science, 2006. 278(1-2): p. 114-123.

29. Cath, T.Y., A.E. Childress, and M. Elimelech, Forward osmosis: Principles, applications, and recent developments. Journal of Membrane Science, 2006. 281(1-2): p. 70-87.

30. Robinson, R.A. and R.H. Stokes, Electrolyte solutions, the measurement and interpretation of conductance, chemical potential, and diffusion in solutions of simple electrolytes. $2 \mathrm{~d}$ ed. 1959, London,: Butterworths Scientific Publications. 559 p.

31. Karan, S., Z.W. Jiang, and A.G. Livingston, Sub-10 $\mathrm{nm}$ polyamide nanofilms with ultrafast solvent transport for molecular separation. Science, 2015. 348(6241): p. 1347-1351.

32. Zhao, S.F., et al., Recent developments in forward osmosis: Opportunities and challenges. Journal of Membrane Science, 2012. 396: p. 1-21.

33. Zhang, S., et al., Well-constructed cellulose acetate membranes for forward osmosis: Minimized internal concentration polarization with an ultra-thin selective layer. Journal of Membrane Science, 2010. 360(1-2): p. 522-535.

34. Wang, K.Y., R.C. Ong, and T.S. Chung, Double-Skinned Forward Osmosis Membranes for Reducing Internal Concentration Polarization within the Porous Sublayer. Industrial \& Engineering Chemistry Research, 2010. 49(10): p. 4824-4831.

35. Freger, V., Swelling and morphology of the skin layer of polyamide composite membranes: An atomic force microscopy study. Environmental Science \& Technology, 2004. 38(11): p. 3168-3175.

36. Zhang, S., F.J. Fu, and T.S. Chung, Substrate modifications and alcohol treatment on thin film composite membranes for osmotic power. Chemical Engineering Science, 2013. 87: p. 40-50.

37. Tang, C.Y.Y., et al., Coupled effects of internal concentration polarization and fouling on flux behavior of forward osmosis membranes during humic acid filtration. Journal of Membrane Science, 2010. 354(1-2): p. 123-133.

38. Hoek, E.M.V., S. Bhattacharjee, and M. Elimelech, Effect of membrane surface roughness on colloid-membrane DLVO interactions. Langmuir, 2003. 19(11): p. 4836-4847.

39. Wei, J., et al., Synthesis and characterization of flat-sheet thin film composite forward osmosis membranes. Journal of Membrane Science, 2011. 372(1-2): p. 292-302.

40. Lee, S. and M. Elimelech, Relating organic fouling of reverse osmosis membranes to intermolecular adhesion forces. Environmental Science \& Technology, 2006. 40(3): p. 980987.

41. Xiang, Y., et al., Hydrated Polyamide Membrane and Its Interaction with Alginate: A Molecular Dynamics Study. Langmuir, 2013. 29(37): p. 11600-11608. 
42. Xiang, Y., et al., Molecular Dynamics Simulations of Polyamide Membrane, Calcium Alginate Gel, and Their Interactions in Aqueous Solution. Langmuir, 2014. 30(30): p. 9098-9106.

43. Mara, D.D. and N.J. Horan, Handbook of water and wastewater microbiology. 2003, London ; San Diego: Academic Press. ix, 819 p.

44. Motsa, M.M., et al., Organic fouling in forward osmosis membranes: The role of feed solution chemistry and membrane structural properties. Journal of Membrane Science, 2014. 460: p. 99-109.

45. Youngjin Kim, S.L., Jihoon Kuk, Seungkwan Hong, Surface chemical heterogeneity of polyamide RO membranes: Measurements and implications. Desalination, 2015. 367: p. 154160. 